\title{
Rational Design of Broadly Absorbing Boron Dipyrromethene- Carbazole Dyads for Dye-Sensitized Solar Cells: A DFT Study
}

\author{
Ata Ur Rahman,* Muhammad Bilal Khan, Muhammad Yaseen, and Gul Rahman* \\ Cite This: ACS Omega 2021, 6, 27640-27653 \\ Read Online
}

ACCESS |

Llll Metrics \& More

Article Recommendations

Supporting Information

ABSTRACT: Structure engineering of boron dipyrromethene (BODIPY) organic dye, to increase its light-harvesting efficiency in dye-sensitized solar cells, has been the subject of rigorous research recently. Herein, we report on the rational designing of BODIPY-carbazole (D- $\pi$-A-A) dyads using density functional theory (DFT). The structure of BODIPY-carbazole was first modified by substituting an electron-donating $-\mathrm{N}\left(\mathrm{CH}_{3}\right)_{2}$ group at the electron-rich carbazole moiety, and two electron-accepting $-\mathrm{COOH}$ groups at the BODIPY core. The DFT calculations showed a significant lowering of the band gap from $2.9 \mathrm{eV}$ (pristine BODIPY-carbazole dyad) to $1.87 \mathrm{eV}$ (modified BODIPY-carbazole dyad). Further modification was demonstrated by the incorporation of heterocyclic rings such as thiophene (denoted as D1T), furan (D1F), and phosphole (D1P) into BODIPY-carbazole moiety, which red-shifted the light absorption spectra and consequently improved the light-harvesting efficiency of the dyes. The interactions at the dye/semiconductor interface were studied by employing their bridged-bidentate adsorption models over the titanium dioxide $\left(\mathrm{TiO}_{2}\right)_{38}$ nanocluster. Results suggested that the electrons can be efficiently injected from the lowest unoccupied molecular orbital (LUMO) of dyes into the conduction band of $\mathrm{TiO}_{2}$. Among the three dyads, D1P exhibited superior photovoltaic performance with a maximum power conversion efficiency of $13.50 \%$, a shortcircuit current density $\left(J_{\mathrm{sc}}\right)$ of $27.2 \mathrm{~mA} \cdot \mathrm{cm}^{-2}$, and an open-circuit voltage $\left(V_{\mathrm{oc}}\right)$ of $731 \mathrm{mV}$. The structurally configured new D1P dye can be used as a potential alternative photosensitizer for high-performance dye-sensitized solar cells.

\section{INTRODUCTION}

The worldwide consumption of energy is continuously growing due to the exponential increase in world's population and industrialization, which has caused the diminishing supply of fossil fuels. ${ }^{1,2}$ Significant research efforts have been devoted to explore the possibilities of low-cost, green, and sustainable alternative energy technologies. ${ }^{3}$ In this regard, dye-sensitized solar cells (DSSCs), which convert solar energy into electricity, have been perceived as promising candidates due to their lowcost and facile fabrication. ${ }^{4,5}$ The DSSCs, since their invention in $1991,{ }^{6}$ have been widely studied as a low-cost alternative to conventional silicon and GaAs solar cells with an efficiency of more than $14 \%{ }^{7,8}$ A DSSC consists of a semiconducting photoanode, generally titanium dioxide $\left(\mathrm{TiO}_{2}\right)$ loaded with a sensitizer dye. The sensitizer dye molecule gets excited when the photoanode is exposed to sunlight. An electron is injected into the conduction band (CB) of $\mathrm{TiO}_{2}$ by the dye in its excited state. The oxidized dye is restored by accepting an electron from the electrolyte, which will receive an electron from the counter electrode thereafter. In recent years, researchers have focused on the various components of DSSCs to improve their efficiency. For example, Cu-based redox couples have been developed to substitute for the traditional $\mathrm{I}^{-} / \mathrm{I}_{3}$ electrolyte recently. ${ }^{9}$ Solid-state electrolytes have been used in place of liquid electrolytes with some of the highest efficiency values of $8.211^{10}$ and $11 \%{ }^{11}$ achieved recently.
The jelly pastes of $\mathrm{TiO}_{2}$ nanoparticle aggregations have been prepared and used as semiconductors in DSSCs for the first time. ${ }^{12}$ Although modifications in other components have shown improvements in the performance of DSSCs, much attention is needed in the development of light-harvesting components, i.e., dye, which plays a vital role in determining the power conversion efficiency of the DSSCs. Therefore, researchers have focused on the various experimental and theoretical aspects of the dyes. Maxime et al. synthesized benzodthiadiazole dyes and utilized them as photosensitizers on a $\mathrm{TiO}_{2}$ semiconductor with an efficiency of up to $10.9 \% .{ }^{13}$ Al-Fouri et al. prepared a bioinspired family of bipodal organic dyes with the D- $\pi$-D-A structure having two triphenylamine (TPA) units as a donor and two cyanoacetic acid units as acceptors. They performed structural modifications in the dyes and obtained good results. ${ }^{14}$ Yang et al. designed a series of dithienopicenocarbazole dyes using density functional theory (DFT) and time-dependent DFT (TD-DFT) methods. They

Received: April 21, 2021

Accepted: October 4, 2021

Published: October 18, 2021

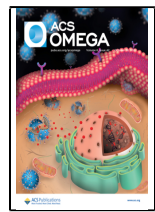



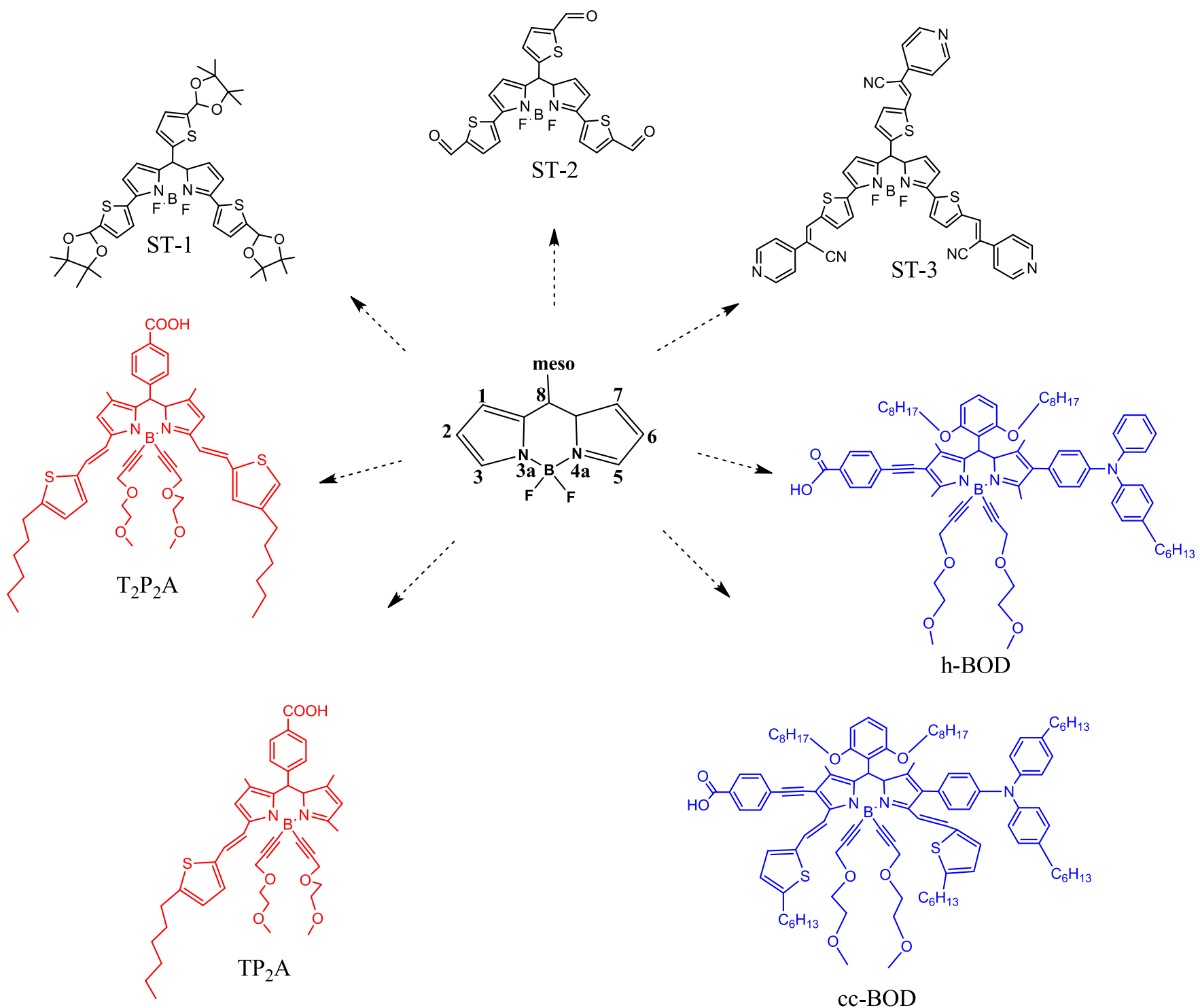

Figure 1. BODIPY derivates (h-BOD $\left.{ }^{34}, \mathrm{cc}-\mathrm{BOD}^{34}, \mathrm{TP}_{2} \mathrm{~A}^{35}, \mathrm{~T}_{2} \mathrm{P}_{2} \mathrm{~A}^{35}, \mathrm{ST}-1^{36}, \mathrm{ST}-2^{36}, \mathrm{ST}-3^{36}\right)$ obtained by the functionalization of various positions.

focused on the effect of changing the acceptor groups of the reported dye $\mathrm{C} 281$ with $\mathrm{D}-\pi$-A on their electronic and physical characteristics. $^{15}$ Montiel et al. designed metal-free organic dyes with carbazole as the donor unit and cyanoacrylic acid as the acceptor groups. They introduced various $\pi$ bridges and performed a theoretical study on the electronic properties of the dyes. ${ }^{16}$ Velayudhan et al. performed a computational study on the photoelectrochemical properties of a series of designed dyes with butadiene unit as the $\pi$ spacer and cyanoacrylic acid group as the acceptor. They focused on the influence of various electron-rich nitrogen-donating groups on the performance of the dyes. ${ }^{17}$

To achieve high-efficiency DSSCs, different classes of sensitizers including ruthenium complexes, ${ }^{18,19}$ porphyrins, ${ }^{20}$ quantum dots, ${ }^{21}$ chlorophyll-based dyes, ${ }^{22}$ and metal-free organic dyes ${ }^{23,24}$ have been reported. These photosensitizers can broadly be divided into two major types: metal and metalfree dyes such as carbazole, ${ }^{25}$ indoline, ${ }^{26}$ coumarine, ${ }^{27}$ phosphole, $^{28}$ thiophene, ${ }^{29}$ triphenylamine, ${ }^{30}$ and boron dipyrromethene (BODIPY). ${ }^{31,32}$ The ruthenium-based sensitizers, such as N3 and black dyes, attributed to their wide absorption spectrum and high stability, have been regarded as champion dyes and have been employed as a standard of comparison for other sensitizers. ${ }^{33}$ However, ruthenium is scarce $^{34}$ and not environmentally friendly. ${ }^{35}$

The BODIPY dyes, among the various organic dyes, have emerged as excellent photosensitizers due to their easy preparation, $^{36}$ high stability, ${ }^{37}$ and tunable nature. ${ }^{38}$ The BODIPY dyes were first synthesized by Treibs and Kreuzer in 1968. ${ }^{39}$ Shunichi et al. applied BODIPY in DSSCs for the first time in $2005^{40}$ and obtained a conversion efficiency of $0.13-$ $0.16 \%$. Since then, researchers have made efforts to modify the structure of BODIPY by attaching different donor and acceptor groups ${ }^{41}$ as well as introducing heterocyclic aromatic rings into the BODIPY framework ${ }^{42}$ at various positions as shown in Figure 1. Recently, Shah et al. synthesized crossconjugated BODIPY dyes by attaching electron donor groups at positions 2, 3, and 5 and an electron acceptor group at position 6 and obtained an efficiency of up to $6.2 \% .{ }^{43}$ Imato et al. functionalized the 3,5 , and 8 positions of the BODIPY framework and synthesized 3,5,8-trithienyl-BODIPY dyes. ${ }^{44}$ They observed that all of the designed dyes exhibited bathochromic shifts due to the extension of $\pi$-conjugation. Islam et al. incorporated bis-thienyl vinyl and thienothiophene 

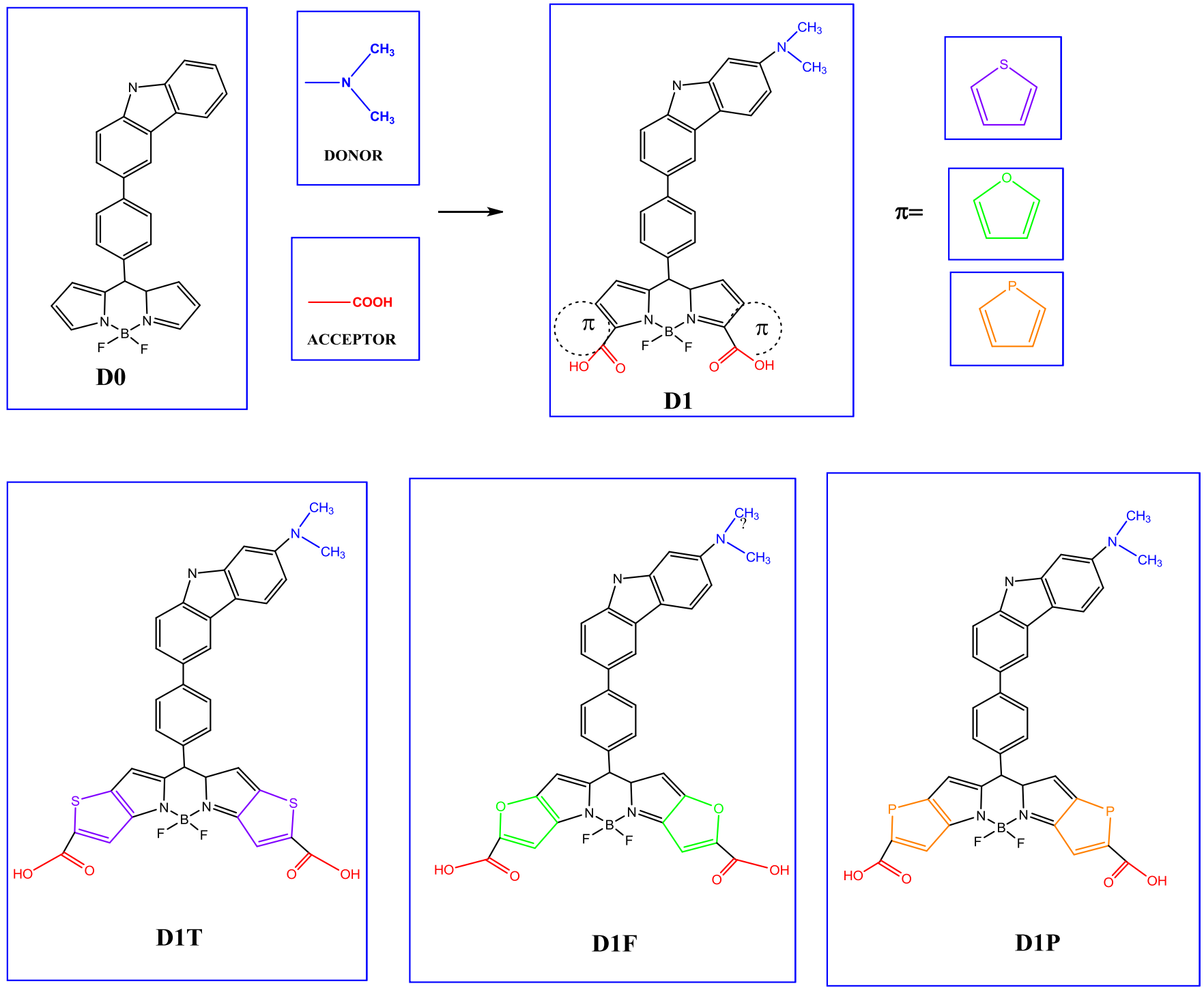

Figure 2. Molecular structures of the designed dyes (D0, D1, D1T, D1F, and D1P).

vinyl substituents in the BODIPY core and obtained a conversion efficiency of up to $6.67 \%{ }^{45}$

One of the major limitations faced by the BODIPY dyes is their narrow light absorption spectrum responsible for their low performance. ${ }^{46,47}$ This disadvantage, as has been demonstrated by previous research, ${ }^{48}$ can be overcome by connecting the BODIPY core and an electron-rich carbazole unit resulting in a significant bathochromic shift. Thayumananvan et al. substituted hexyl-substituted carbazole unit to the BODIPY unit at the meso position through a phenyl ring as a $\pi$-spacer and obtained BODIPY-carbazole dyads that showed maximum absorption at $497 \mathrm{~nm} .{ }^{49}$ Gupta et al. synthesized a series of meso-substituted BODIPY-carbazole dyads. They obtained maximum absorption wavelength from 498 to 529 $\mathrm{nm}$ extending up to $600 \mathrm{~nm} .{ }^{50}$ However, little attention has been paid to the theoretical aspects of tuning the photoelectric properties of organic dyes. ${ }^{51}$ Therefore, with the aim of additional improvement of the photoelectrochemical properties of BODIPY-carbazole dyads, to lower the band gaps and extend the light absorption spectra up to the near-IR region, we demonstrated a detailed theoretical investigation into their structural modification. For the sake of computational simplicity, we replaced the hexyl chain at the nitrogen atom in carbazole moiety and methyl groups at the BODIPY core by hydrogen atoms. The electron-donating dimethylamine $-\mathrm{N}$ $\left(\mathrm{CH}_{3}\right)_{2}$ group was bonded to carbazole moiety, and two electron-accepting carboxylate groups were attached at the BODIPY core. It was observed that the substitution of electron-donating and electron-accepting groups resulted in a significant decrease in the band gap. Further improvement was achieved by fusing thiophene, furan, and phosphole rings in the BODIPY core, which resulted in the red-shifting of the light absorption spectra and improved the power conversion efficiency of the DSSC (Figure 2).

\section{RESULTS AND DISCUSSION}

2.1. Geometrical Structure Optimization. The absorption spectrum, the transfer of electrons within the molecule and eventually to the $\mathrm{TiO}_{2} \mathrm{CB}$, and the solar cell performance depend upon the geometrical structure of the dye. ${ }^{32} \mathrm{~A}$ molecule with a higher degree of planarity will have better $\pi$ conjugation and wider light absorption spectrum. ${ }^{52,53}$ In addition to this, previous research has also demonstrated that higher planarity will promote better intramolecular charge 


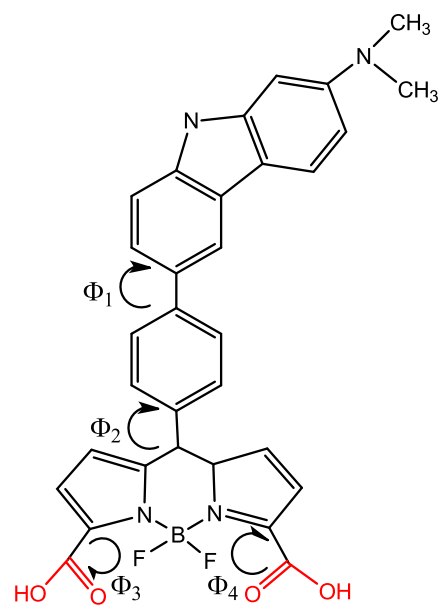

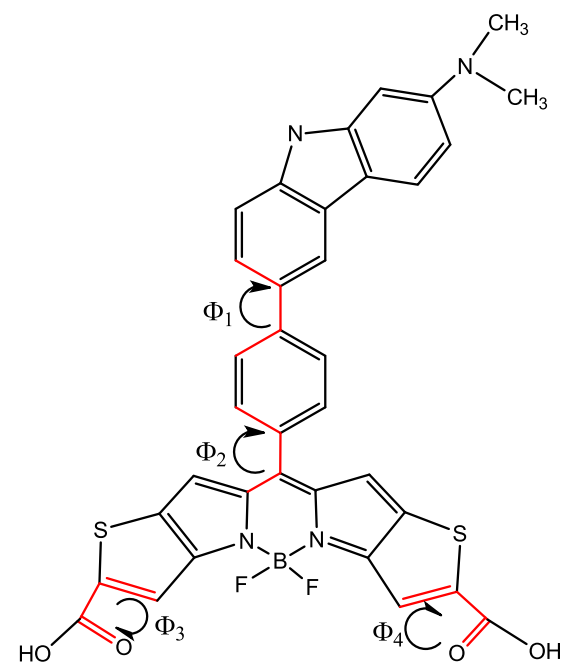

$\Phi=$ Dihedral Angles

Figure 3. Critical dihedral angle positions of the dye molecules (D0, D1, D1T, D1F, and D1P).

transfer (ICT) ${ }^{54}$ Therefore, the critical dihedral angles of the molecules D0, D1, D1T, D1F, and D1P, as shown in Figure 3, were calculated and are presented in Table 1 . The optimized

Table 1. Critical Dihedral Angles of All of the Designed Dye Molecules (D0, D1, D1T, D1F, and D1P)

\begin{tabular}{lccrc}
\hline dye & $\Phi_{1}$ & $\Phi_{2}$ & $\Phi_{3}$ & $\Phi_{4}$ \\
\hline D0 & 39.07 & 54.58 & & \\
D1 & 37.33 & 54.53 & 5.69 & 7.01 \\
D1T & 36.87 & 53.90 & 0.06 & 0.03 \\
D1F & 36.93 & 54.74 & -0.04 & 0.01 \\
D1P & 37.37 & 53.82 & 1.65 & 1.61 \\
\hline
\end{tabular}

structures of these dyes are shown in Figure $S 1$ in the Supporting Information. The critical dihedral angles between the carbazole moiety and phenyl ring, phenyl ring and the BODIPY core, and the BODIPY core and the anchoring groups on both sides are represented by $\Phi_{1}, \Phi_{2}, \Phi_{3}$, and $\Phi_{4}$, respectively. In the case of D0, the dihedral angles $\Phi_{3}$ and $\Phi_{4}$ do not exist. The values of dihedral angle $\Phi_{1}$ are $39.07^{\circ}$, $37.33^{\circ}, 36.87^{\circ}, 36.93^{\circ}$, and $37.37^{\circ}$ for D0, D1, D1T, D1F, and $\mathrm{D} 1 \mathrm{P}$, respectively. It can be seen that the introduction of an electron-donating group leads to the lowering of the dihedral angle $\Phi_{1}$, which is beneficial for the planarity of the molecules. On the other hand, the value of dihedral angle $\Phi_{2}$ is $54.58^{\circ}$, $54.53^{\circ}, 53.91^{\circ}, 54.74^{\circ}$, and $53.82^{\circ}$ for D0, D1, D1T, D1F, and $\mathrm{D} 1 \mathrm{P}$, respectively. Because of the strong $\pi$ electron repulsion between the phenyl ring and the BODIPY core, the molecular structure gets twisted at the dihedral angle $\Phi_{2}$. Studies show that this twist in the molecule leads to charge separation between the highest occupied molecular orbital (HOMO) and the lowest unoccupied molecular orbital (LUMO) of the molecule, preventing dye aggregation, which ultimately enhances the photovoltaic performance. ${ }^{55}$ The transfer of electrons to the $\mathrm{CB}$ of $\mathrm{TiO}_{2}$ from the LUMO of the dye occurs

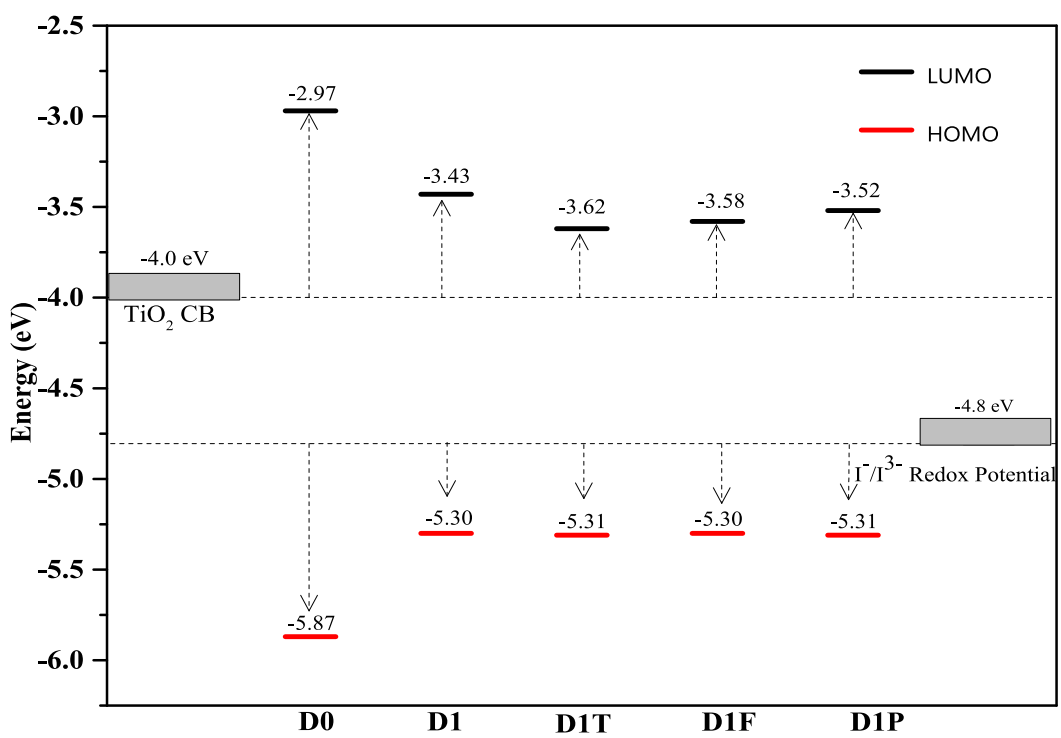

Figure 4. HOMO-LUMO energy band gap diagram for all of the designed dyes (D0, D1, D1T, D1F, and D1P) calculated at the DFT/B3LYP/6$311 \mathrm{G}(\mathrm{d}, \mathrm{p})$ level of theory along with the $\mathrm{CB}$ energy level of $\mathrm{TiO}_{2}$ and redox potential of $\mathrm{I}^{-} / \mathrm{I}_{3}{ }^{-}$redox couple. 
through the carboxylate anchoring group. Therefore, the dihedral angles $\Phi_{3}$ and $\Phi_{4}$ play a crucial role. A higher degree of planarity between the BODIPY core and the carboxylate anchoring group will facilitate faster electron injection in the $\mathrm{TiO}_{2} \mathrm{CB}$. It can be seen from Table 1 that the values of these dihedral angles are $5.69^{\circ}$ and $7.01^{\circ}$, respectively, while these values of $\mathrm{D} 1 \mathrm{~T}, \mathrm{D} 1 \mathrm{~F}$, and $\mathrm{D} 1 \mathrm{P}$ are close to zero, which suggests that electrons can be efficiently transferred from the dye into the $\mathrm{CB}$ of $\mathrm{TiO}_{2}$.

2.2. Frontier Molecular Orbitals (FMOs) of the Designed Dyes. The photoelectrochemical properties such as the shape of light absorption spectra and chemical reactivity of molecules can very well be explained on the basis of the frontier molecular orbital theory. ${ }^{56}$ Therefore, the FMOs of D1, D1T, D1F, and D1P dyes were calculated. It was observed that D1, D1T, D1F, and D1P displayed $\pi-\pi^{*}$ electronic transitions, which are caused by the photoexcitation of the dye resulting in the shifting of electron density from HOMO to LUMO as shown in Figure 4 and the respective data as listed in Table 2. The LUMO of the dye should be considerably

Table 2. HOMOs, LUMOs, and the HOMO-LUMO Gaps of All of the Designed Dyes (D0, D1, D1T, D1F, and D1P)

\begin{tabular}{lccccc} 
energy level & D0 & D1 & D1T & D1F & D1P \\
\hline HOMO & -2.97 & -5.30 & -5.31 & -5.31 & -5.31 \\
LUMO & -5.87 & -3.34 & -3.62 & -3.58 & -3.52 \\
band gap & -2.90 & -1.96 & -1.69 & -1.73 & -1.79 \\
\hline
\end{tabular}

positive compared to the $\mathrm{CB}$ of $\mathrm{TiO}_{2}$. It has been reported that the $\mathrm{CB}$ of $\mathrm{TiO}_{2}$ is at $-4.0 \mathrm{eV},{ }^{57}$ which allows the efficient falling of electron from the dye $\mathrm{LUMO}$ to the $\mathrm{TiO}_{2} \mathrm{CB}$. As the dye loses its electron to the $\mathrm{CB}$ of $\mathrm{TiO}_{2}$, it takes up an electron from the electrolyte so that it can be restored. Therefore, another essential requirement is the suitable match of energy levels between the electrolyte redox potential at $-4.8 \mathrm{eV}^{58}$ and the HOMO of dye, which will provide an efficient driving force for the regeneration of dye. The energy levels of the $\mathrm{CB}$ of $\mathrm{TiO}_{2}$ and the redox potential of the $\mathrm{TiO}_{2}$ are also shown in Figure 4. For efficient electron injection to occur, the dye LUMO should be at least $0.2 \mathrm{eV}$ positive to the $\mathrm{CB}$ of $\mathrm{TiO}_{2} .{ }^{59}$ The LUMO energy levels of D1T, DIF, and DIP were at $-3.62,-3.58$, and $-3.52 \mathrm{eV}$, respectively, making them positive enough compared to the $\mathrm{CB}$ of $\mathrm{TiO}_{2}$. A comparison was made between the band gaps of D0 and that of D1, D1T, $\mathrm{D} 1 \mathrm{~F}$, and D1P as to see the effect of substituting electrondonating groups and electron-accepting groups as well as fusing the heterocyclic rings in the BODIPY core on the HOMO and LUMO energy levels. It is evident from Figure 3 that the band gap of the D0 is $2.91 \mathrm{eV}$, and after the attachment of the electron-donating group and electronaccepting groups, a marked reduction was observed in the band gap. The band gaps of D1, DIT, DIF, and DIP were lying at $1.87,1.69,1.73$, and $1.79 \mathrm{eV}$, respectively. The introduction of the electron-donating group makes the HOMO more positive and that of the electron-accepting group makes the LUMO more negative causing the band gap to lower. ${ }^{60}$ The fusion of the heterocyclic thiophene, furan, and phosphole rings also affects the band gap as they increase the $\pi$ conjugation. $^{61}$ All of the dye HOMO levels are almost the same, but the LUMO levels differ. The LUMOs of the dye molecule containing thiophene ring is the lowest, which can be attributed to the larger size of the sulfur atom leading to better $\pi$-conjugation.

It is the HOMO-LUMO energy gap that governs the important transitions between various electronic states and decides the light absorption spectrum and the dye electron injection properties. The smaller HOMO-LUMO gap

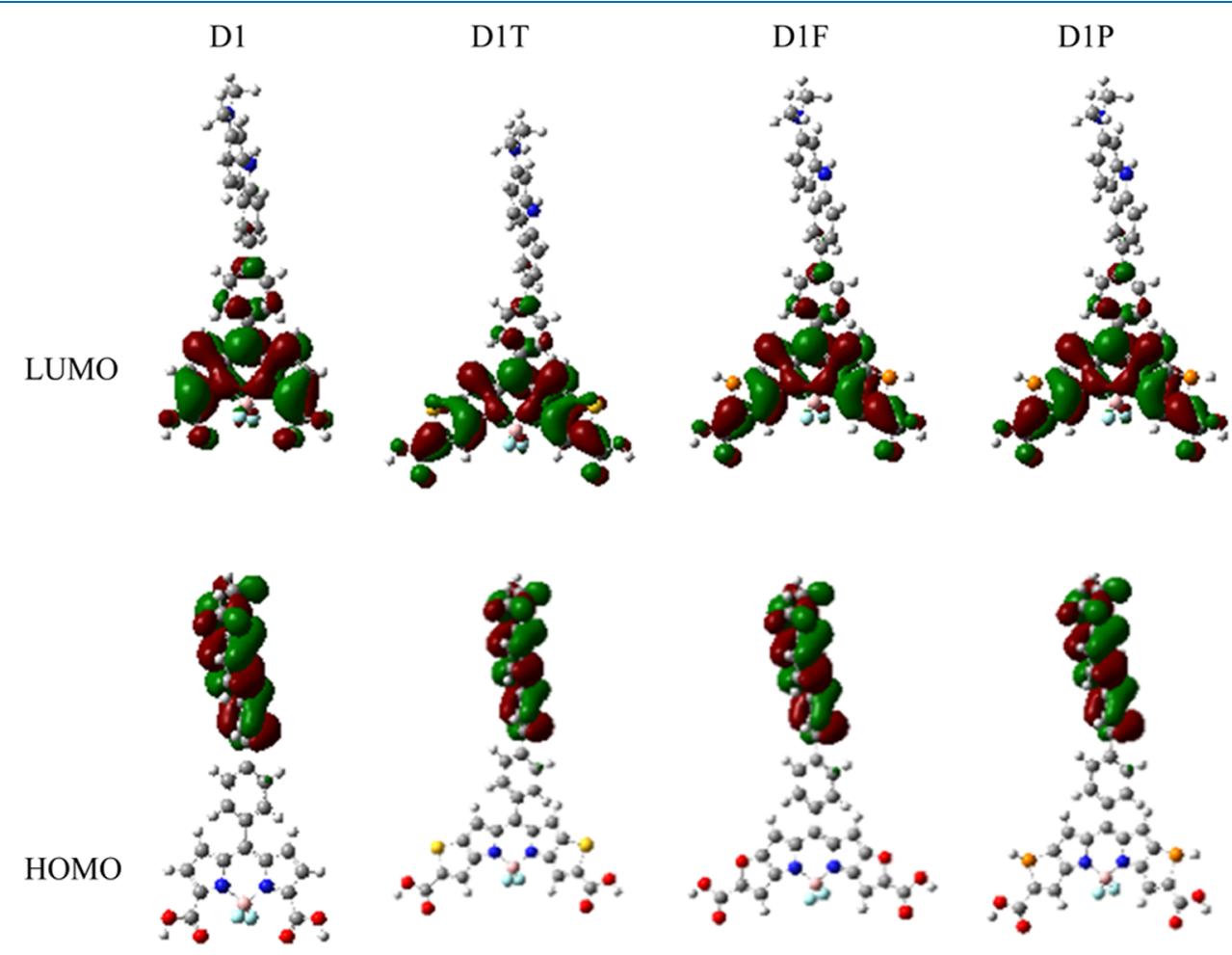

Figure 5. Frontier molecular orbitals of the designed dyes (D1, D1T, D1F, and D1P) calculated at the DFT/B3LYP/6-311G (d,p) level of theory. 

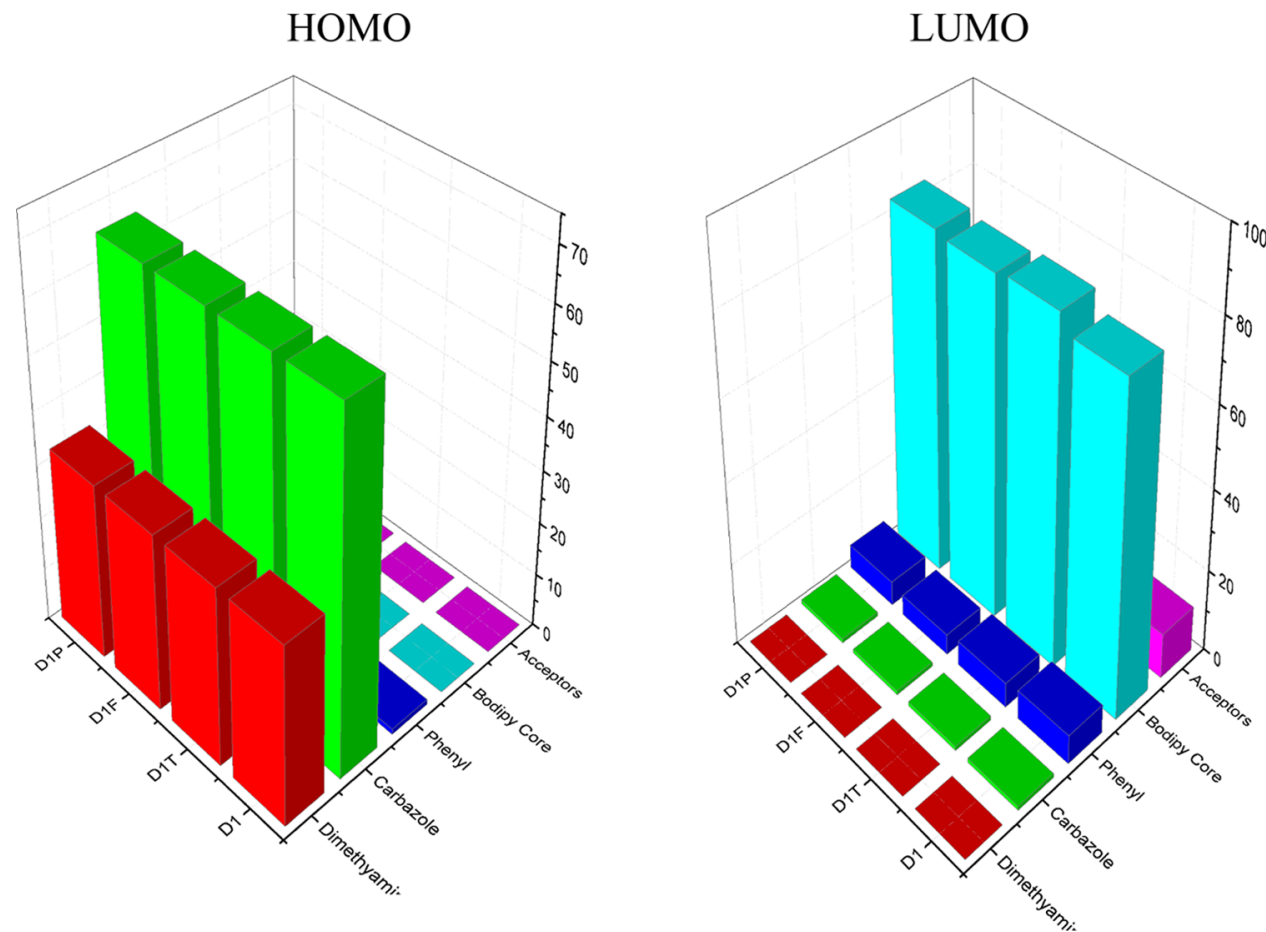

Figure 6. Percent contribution of electron density of different groups of the dye molecules (D1, D1T, D1F, and D1P).

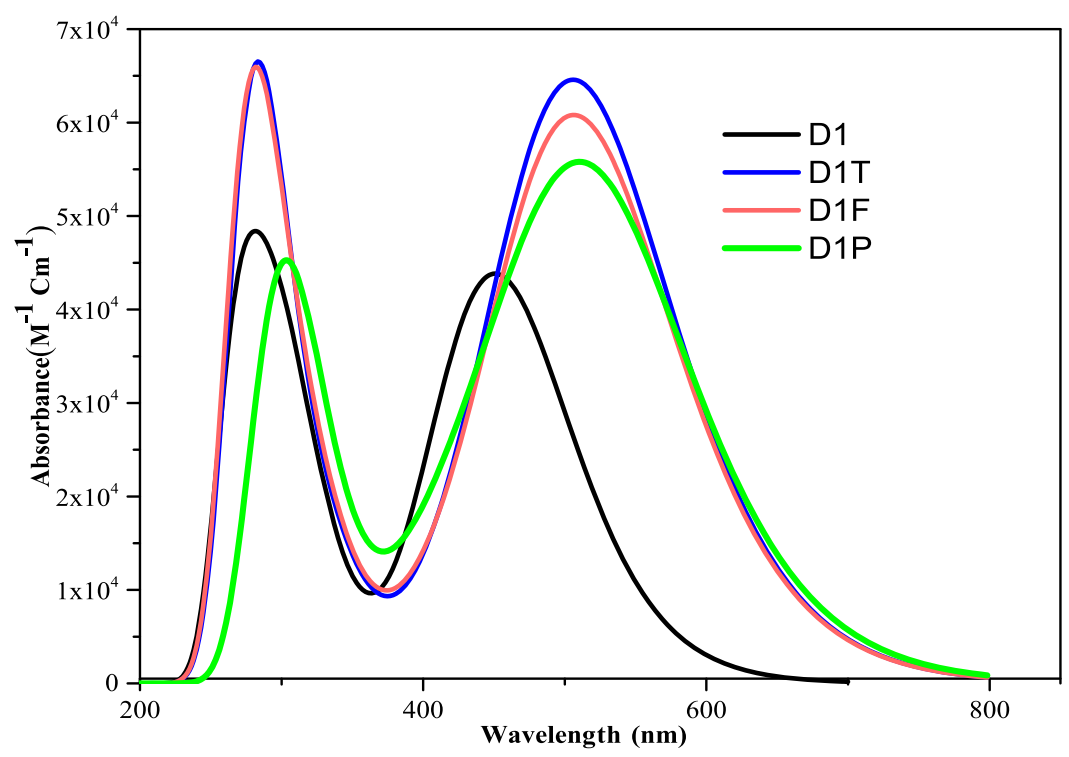

Figure 7. UV-vis absorption spectra of all of the designed dyes (D1, D1T, D1F, and D1P).

corresponds to a more convenient electronic transition leading to a wide absorption spectrum giving rise to a larger photocurrent response. Therefore, the electronic density distribution of all dye HOMOs and LUMOs were calculated and are presented in Figure 5. The separation of electronic density, after the absorption of radiation by the dye molecule, between the electron-rich center and electron-deficient center, prevents dye aggregation, leading to better intramolecular charge transfer (ICT). ${ }^{62}$ In an efficient photosensitizer, the HOMO orbitals should be situated on the donor portion of the molecules and the LUMO orbitals should be located on the acceptor part within the molecule. It is obvious that the HOMOs of D1, D1T, D1F, and D1P are located on the dimethylamine and carbazole moiety, while the LUMOs are located on the BODIPY and acceptor units of the molecule as a result the electron density moves from HOMO to LUMO upon photoexcitation. It can be seen that the designed dyes $\mathrm{D} 1, \mathrm{D} 1 \mathrm{~T}, \mathrm{D} 1 \mathrm{~F}$, and D1P possess good charge separation, which gives rise to an efficient ICT within the molecule and high solar cell performance. The percentage compositions of each group toward the HOMO and LUMO orbitals were also calculated and are presented in Figure 6. The HOMO orbitals of the dyes D1, D1T, D1F, and D1P are mainly contributed by the carbazole moiety (66\%) and the dimethylamine group (33\%). The contribution of LUMO orbitals of D1 comes from the BODIPY core $(80 \%)$, acceptor groups (11\%), phenyl ring (7\%), and carbazole moiety (1\%). The LUMOs of the dyes D1T, D1F, and D1P have almost similar percent contributions. 
The LUMO of D1T is mainly contributed by the BODIPY core $(84 \%)$, acceptor groups (9\%), phenyl ring $(6 \%)$, and carbazole moiety (1\%). In the case of D1F, the LUMO orbital also mainly arises from the BODIPY core (83\%), acceptor groups (10\%), phenyl ring (5\%), and carbazole moiety (1\%). Similarly, the LUMO orbitals of D1P are contributed by the BODIPY core (84\%), acceptor groups (9\%), phenyl ring (6\%), and the carbazole moiety (1\%). It can be seen that the incorporation of aromatic rings can lead to more electron density toward the acceptor side of the molecule.

2.3. Short-Circuit Current Density. The light-harvesting efficiency (LHE) is a crucial parameter in determining the performance of DSSCs as it directly influences the short-circuit current density. A DSSC with a broad LHE curve will yield a greater short-circuit current density leading to an enhanced DSSC performance. The LHE in turn depends upon the light absorption spectrum of the dye, which is a basic requirement for the high-performance of DSSC. A wider light absorption spectrum corresponds to a high LHE of the dyes. ${ }^{51}$ The dye should absorb in the entire ultraviolet (UV), visible (vis), and near-infrared (IR) regions. The simulated UV-vis spectra of D1, D1T, D1F, and D1P dyes are shown in Figure 7, and the spectroscopic data are presented in Table 3, which suggests

Table 3. Spectroscopic Parameters of All of the Designed Dyes (D1, D1T, D1F, and D1P)

\begin{tabular}{lccc}
$\begin{array}{c}\text { type of } \\
\text { dye }\end{array}$ & $\begin{array}{c}\text { maximum absorption } \\
\text { wavelength } \lambda_{\max }(\mathrm{nm})\end{array}$ & $\begin{array}{c}\text { oscillator } \\
\text { strength }(f)\end{array}$ & $\begin{array}{c}\text { type of } \\
\text { transition }\end{array}$ \\
D1 & 467.47 & 0.56 & $\pi-\pi^{*}$ \\
D1T & 518.60 & 1.19 & $\pi-\pi^{*}$ \\
D1F & 519.15 & 1.18 & $\pi-\pi^{*}$ \\
D1P & 527.41 & 1.13 & $\pi-\pi^{*}$ \\
\hline
\end{tabular}

that all of the dyes gave two main absorption peaks in the ranges of $200-400$ and $400-800 \mathrm{~nm}$. It can be seen that the absorption peaks of D1T, D1F, and D1P are broader than that of the D1 and even extend to the near-IR region, suggesting that the attachment of the heterocyclic rings into the BODIPY core causes a significant redshift of the absorption spectra in the visible region. These absorption peaks can be attributed to the $\pi-\pi^{*}$ electronic transition from HOMO to LUMO commonly found in the D- $\pi$-A sensitizers ${ }^{63}$

The short-circuit current density of the DSSC can be calculated according to eq $1^{64}$

$$
J_{\mathrm{sc}=e} \int_{\lambda 1}^{\lambda 2} \operatorname{LHE}(\lambda) \phi_{\text {inj }} \eta_{\mathrm{coll}} I_{\mathrm{s}} \mathrm{d} \lambda
$$

Here, $e$ is the elementary charge, LHE represents lightharvesting efficiency at a specified wavelength, $\phi_{\text {inj }}$ is the charge injection efficiency, $\eta_{\text {coll }}$ refers to the charge collection efficiency, and $I_{s}(\lambda)$ denotes the photon flux corresponding to AM 1.5G solar radiation spectrum. LHE is calculated from eq $2^{65,66}$

$$
\mathrm{LHE}=1-10^{-\varepsilon(\lambda) b c}
$$

where $\varepsilon(\lambda)$ refers to the molar absorption coefficient at a particular wavelength, $b$ represents the thickness of the semiconductor film, and $\mathrm{c}$ denotes the dye concentration. The film thickness was kept at $10 \mu \mathrm{m}$, and the dye concentration was fixed at $300 \mathrm{mmol} \mathrm{L}^{-1}$. ${ }^{67}$ The $\phi_{\text {inj }}$ and $\eta_{\text {coll }}$ values are calculated, respectively, according to eqs 3 and $4^{66}$

$$
\begin{aligned}
& \phi_{\text {inj }}=\frac{1}{\left(1+\frac{\tau_{\text {inj }}}{\tau_{\text {relax }}}\right)} \\
& \eta_{\text {coll }}=\frac{1}{\left(1+\frac{\tau_{\text {trans }}}{\tau_{\text {rec }}}\right)}
\end{aligned}
$$

where $\tau_{\text {inj }}$ refers to the lifetime of electron injection from the dye LUMO into the CB of $\mathrm{TiO}_{2}$ semiconductor, $\tau_{\text {relax }}$ denotes the excited dye relaxation time in the solution, $\tau_{\text {trans }}$ represents the electron transport time to the counter electrode from the $\mathrm{CB}$ of $\mathrm{TiO}_{2}$, and $\tau_{\text {rec }}$ indicates the charge recombination time. According to the literature, ${ }^{68}$ the value of $\tau_{\text {relax }}$ is set to be $10 \mathrm{ps}$ and that of $\tau_{\text {trans }}$ is set at 2 ps. The $\tau_{\text {inj }}$ and $\tau_{\text {rec }}$ values are calculated according to the Marcus theory. They are equal to $k_{\text {inj }}^{-1}$ and $k_{\text {rec }}^{-1}$, respectively. Due to the extremely small values of $k_{\text {inj }}^{-1}$ and $k_{\text {rec }}^{-1}, \Phi_{\text {inj }}$ and $\eta_{\text {coll }}$ are equated to be $1 .{ }^{51}$

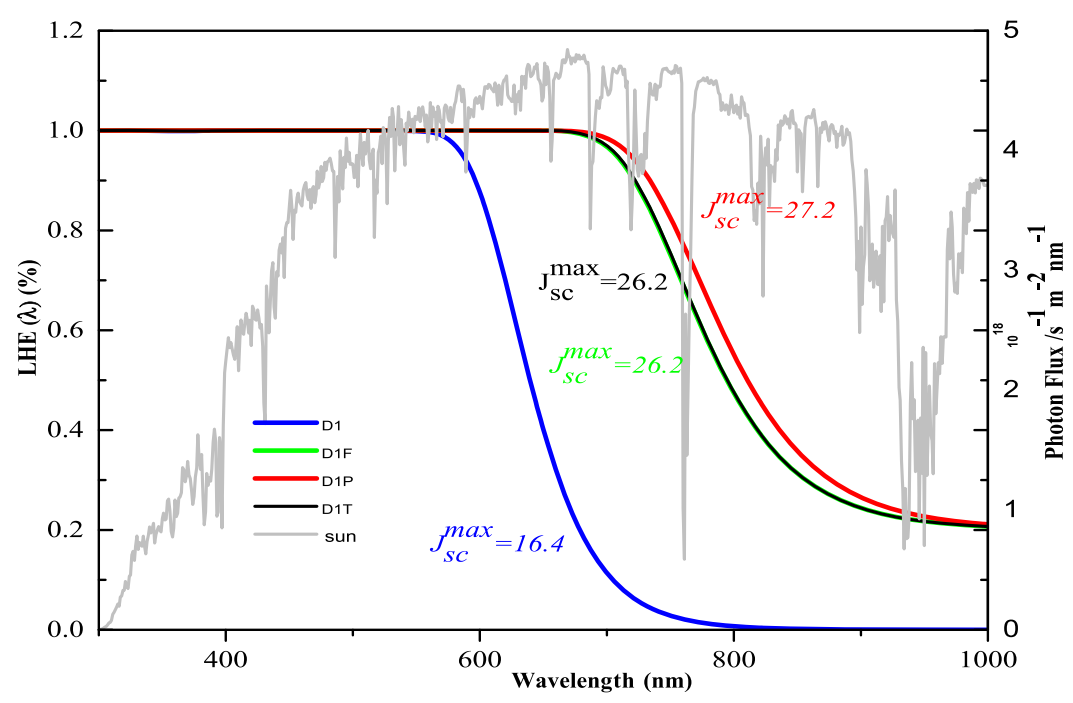

Figure 8. LHE curves and maximum limit short-circuit current density of all designed dyes (D1, D1T, D1F, and D1P). The gray line is AM 1.5 solar spectrum. 

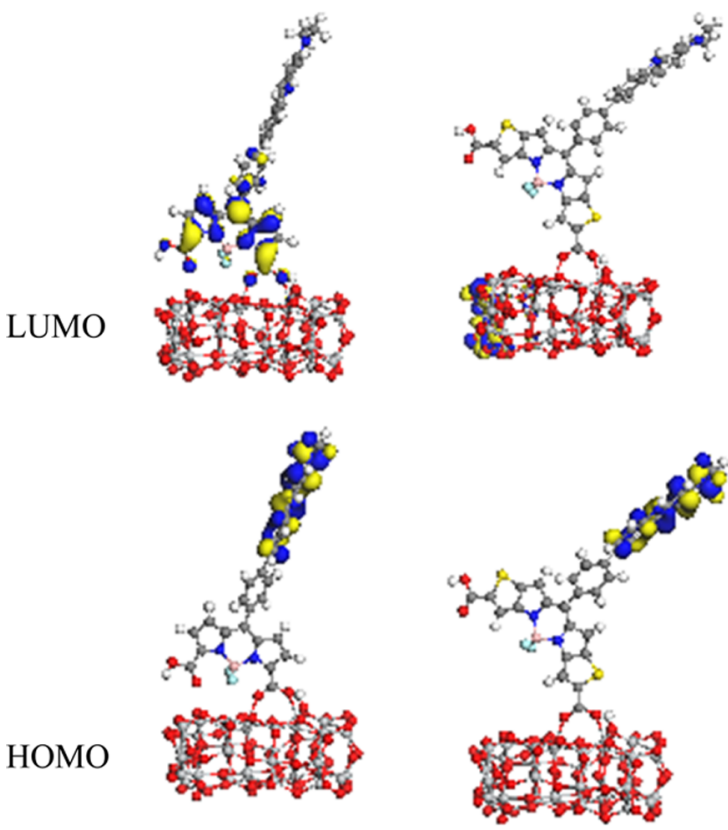

D1T
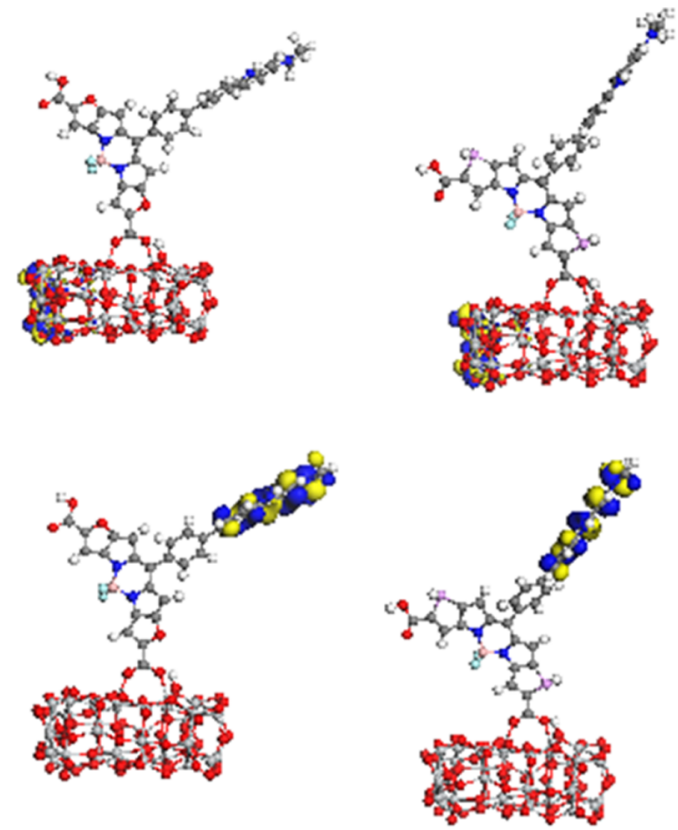

D1F

D1P

Figure 9. Frontier molecular orbitals (FMOs) of all of the designed dyes (D1, D1T, D1F, and D1P) on the surface of $\mathrm{TiO}_{2}$.

The LHE curves of D1F, D1P, and D1T are wider than that of D1, as evident from Figure 8, which suggests that the incorporation of heterocyclic rings in the BODIPY core leads to higher light-harvesting ability. The $J_{\mathrm{sc}}$ values of the designed dyes followed the order: D1P $\left(27.2 \mathrm{~mA} \mathrm{~cm}^{-2}\right)>$ D1T $(26.4$ $\left.\left.\mathrm{mA} \mathrm{cm}{ }^{-2}\right) \sim \operatorname{D} 1 \mathrm{~F}\left(26.4 \mathrm{~mA} \mathrm{~cm}{ }^{-2}\right)>\mathrm{D} 1(16.4 \mathrm{~mA} \mathrm{~cm})^{-2}\right)$, which is in accordance with their respective absorption spectra.

2.4. Dye/ $/ \mathrm{TiO}_{2}$ Adsorbed System. The interactions between D1, D1T, D1F, and D1P dyes and $\mathrm{TiO}_{2}$ semiconductor were studied by constructing their adsorption models, which were simulated by dye molecules adsorbed over the nanocluster of $\left(\mathrm{TiO}_{2}\right)_{38}$. The dye molecules may be adsorbed at the $\left(\mathrm{TiO}_{2}\right)_{38}$ nanocluster through different modes of adsorption, which in this study were constructed in the form of bridged-bidentate adsorption models. In this mode of adsorption, the two oxygen atoms of the carboxylic groups present on the dye molecules get bonded to the 5-coordinated $\mathrm{Ti}$ atoms and hydrogen is transferred to the nearby oxygen atom. The optimized adsorption configurations of all of the designed dyes with their electron distributions over the $\left(\mathrm{TiO}_{2}\right)_{38}$ nanocluster are shown in Figure 9. The structures of the unoptimized, as well as the optimized $\left(\mathrm{TiO}_{2}\right)_{38}$ nanoclusters are shown in Figures S2 and S3. It is observed that the HOMOs of $\mathrm{D} 1 /\left(\mathrm{TiO}_{2}\right)_{38}, \mathrm{D} 1 \mathrm{~T} /\left(\mathrm{TiO}_{2}\right)_{38}, \mathrm{D} 1 \mathrm{~F} /$ $\left(\mathrm{TiO}_{2}\right)_{38}$, and $\mathrm{D} 1 \mathrm{P} /\left(\mathrm{TiO}_{2}\right)_{38}$ complexes are hovering over the electron-rich carbazole unit, while the LUMOs are delocalized over the semiconductor except for $\mathrm{D} 1 /\left(\mathrm{TiO}_{2}\right)_{38}$. This suggests that the newly designed dyes can efficiently transfer their electrons to the $\mathrm{TiO}_{2}$ semiconductor, which gives rise to better photovoltaic performance.

The dye adsorption energy after adsorption on the semiconductor surface can be calculated according to eq 5

$$
E_{\mathrm{ads}}=E_{\mathrm{dye} / \mathrm{TiO}_{2}}-E_{\mathrm{dye}}-E_{\mathrm{TiO}_{2}}
$$

In this equation, $E_{\mathrm{dye}+\mathrm{TiO}_{2}}, E_{\mathrm{dye}}$ and $E_{\mathrm{TiO}_{2}}$ represent the total energy of the dye $/ \mathrm{TiO}_{2}$ complexes, isolated dye, and total energy of the $\left(\mathrm{TiO}_{2}\right)_{38}$ nanocluster, respectively. The values of $E_{\text {dye }}$ are negative suggesting that the dyes are strongly bonded to the semiconductor surface, which leads to improved electron transfer from dye to semiconductor responsible for the higher photoelectric conversion efficiency. The values of $E_{\text {dye }}$ and the bond lengths between the designed dye molecules and $\mathrm{TiO}_{2}$ surface are listed in Table 4.

Table 4. Adsorption Energy $\left(E_{\text {ads }}\right)$ of the Designed Dyes (D1, D1T, D1F, and D1P) Adsorbed on $\mathrm{TiO}_{2}$ Surface and Bond Distance between the Designed Dyes and $\mathrm{TiO}_{2}$ Surface

$\begin{array}{cccc}\text { type of dye } & E_{\text {ads }}(\mathrm{eV}) & \text { bond distance between dyes and } \mathrm{TiO}_{2} & \\ \mathrm{D} 1 & -12.79 & 2.061 & 2.140 \\ \mathrm{D} 1 \mathrm{~T} & -14.14 & 2.055 & 2.169 \\ \mathrm{D} 1 \mathrm{~F} & -14.15 & 2.046 & 2.193 \\ \mathrm{D} 1 \mathrm{P} & -14.70 & 2.050 & 2.158\end{array}$

The dye $/ \mathrm{TiO}_{2}$ interactions can be explored by studying the total density of states (TDOS) and partial density of states (PDOS) for bare $\mathrm{TiO}_{2}$ semiconductor surface and the dye/ $\mathrm{TiO}_{2}$ complexes, respectively, as shown in Figure 10. The DOS diagrams of all of the dye $/ \mathrm{TiO}_{2}$ complexes reveal that the energy band separates the $\mathrm{CB}$ and the valence band (VB). The dye and $\mathrm{TiO}_{2}$ both contribute to the $\mathrm{CB}$, while the valence band is mainly contributed by the dye $/ \mathrm{TiO}_{2}$ system. It can be clearly seen that all of the dye HOMOs and LUMOs together with the $\mathrm{CB}$ minimum (CBM) of $\mathrm{TiO}_{2}$ have shifted to higher values. Furthermore, the HOMO-LUMO gap also reduced to 1.47, 1.48, 1.44, and $1.51 \mathrm{eV}$ for $\mathrm{D} 1 /\left(\mathrm{TiO}_{2}\right)_{38}, \mathrm{D} 1 \mathrm{~T} /\left(\mathrm{TiO}_{2}\right)_{38}$, $\mathrm{D} 1 \mathrm{~F} /\left(\mathrm{TiO}_{2}\right)_{38}$, and $\mathrm{D} 1 \mathrm{P} /\left(\mathrm{TiO}_{2}\right)_{38}$, respectively. The HOMO energy levels have moved to the $\mathrm{CB}$ of $\mathrm{TiO}_{2}$ while the LUMOs are at $0.72,0.77,0.73$, and $0.77 \mathrm{eV}$ for $\mathrm{D} 1 /\left(\mathrm{TiO}_{2}\right)_{38}, \mathrm{D} 1 \mathrm{~T} /$ $\left(\mathrm{TiO}_{2}\right)_{38}, \mathrm{D} 1 \mathrm{~F}\left(\mathrm{TiO}_{2}\right)_{38}$, and D1P, respectively. All of the dye LUMOs are adequately positive compared to the $\mathrm{TiO}_{2} \mathrm{CBM}$. 

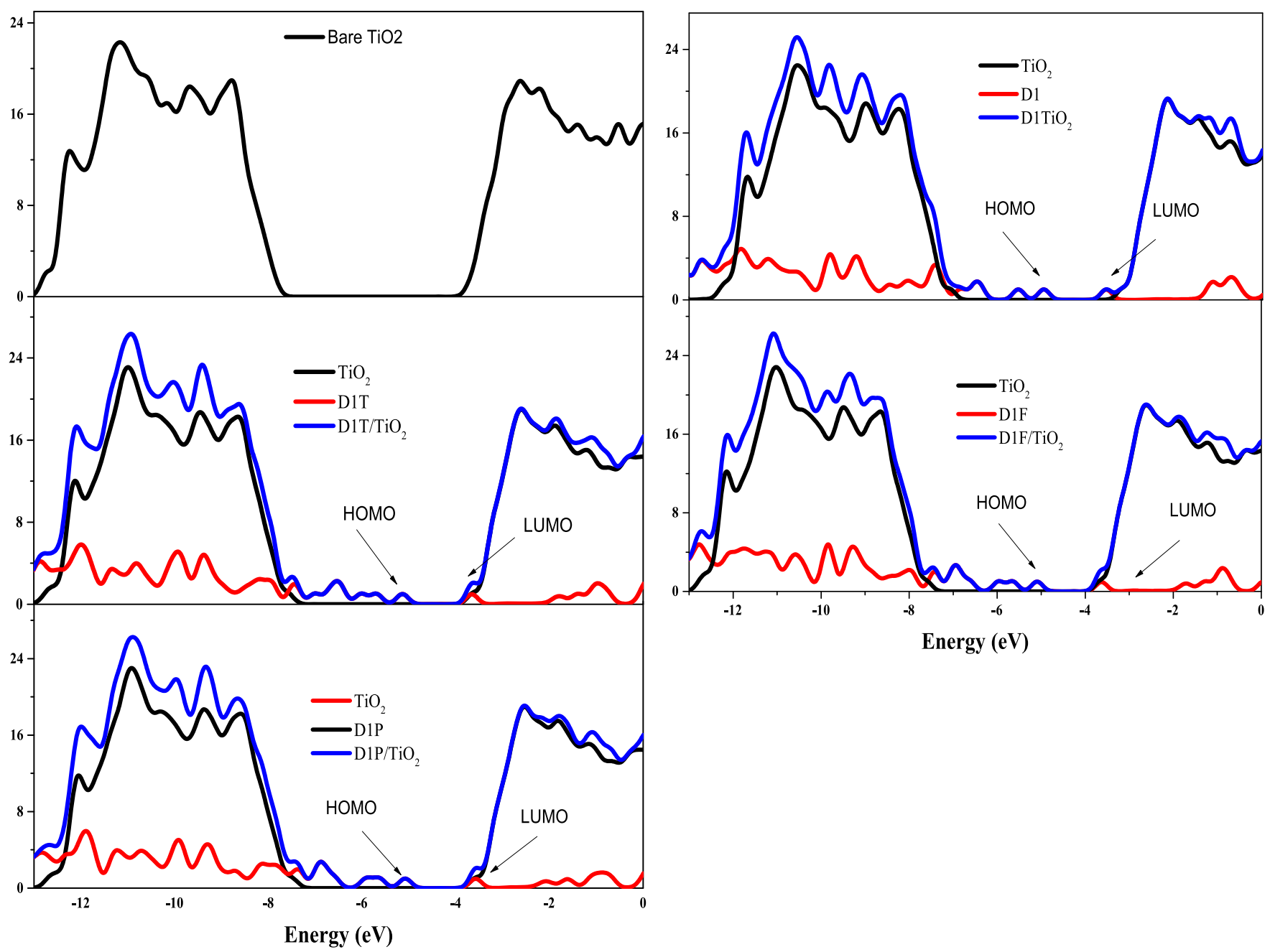

Figure 10. Density of states (DOS) for bare $\mathrm{TiO}_{2}$ and partial density of states (PDOS) for each dye/ $\mathrm{TiO}_{2}$ system.

As a consequence, electrons can be efficiently transferred into the $\mathrm{CB}$ of $\mathrm{TiO}_{2}$ from the LUMO of dye. The calculated CBM of pure $\mathrm{TiO}_{2}$ is $-4.54 \mathrm{eV}$, which is $0.54 \mathrm{eV}$ lower than the experimental value. It can be seen that upon the adsorption of dyes on $\mathrm{TiO}_{2}$ surface, the CBM of $\mathrm{TiO}_{2}$ is increased slightly (from -4.54 to $-4.25 \mathrm{eV}$ ) as shown in Table 5, which is

Table 5. Calculated Driving Force for Electron Injection $\left(\Delta G_{\text {inj }}\right)$ and Excited-State Lifetimes $\left(\tau_{\mathrm{e}}\right)$ for All of the Designed Dyes (D1, D1T, D1F, and D1P)

\begin{tabular}{lccccc}
\multicolumn{1}{c}{ dye $/ \mathrm{TiO}_{2}$} & LUMO & HOMO & CBM & Eg & $\Delta G_{\text {inj }}^{0}$ \\
$\mathrm{D} 1 \mathrm{P} / \mathrm{TiO}_{2}$ & -3.55 & -5.06 & -4.32 & 1.51 & 0.77 \\
$\mathrm{D} 1 / \mathrm{TiO}_{2}$ & -3.53 & -5.0 & -4.25 & 1.47 & 0.72 \\
$\mathrm{D} 1 \mathrm{~T} / \mathrm{TiO}_{2}$ & -3.65 & -5.13 & -4.42 & 1.48 & 0.77 \\
$\mathrm{D} 1 \mathrm{~F} / \mathrm{TiO}_{2}$ & -3.64 & -5.08 & -4.37 & 1.44 & 0.73
\end{tabular}

conducive to the electron injection process. ${ }^{69}$ The highest driving force for injection is shown by D1P and D1T $(0.77 \mathrm{eV}$ each). The shift in the $\mathrm{CBM}$ of $\mathrm{TiO}_{2}$ arises from the dipole moment of the dye lying perpendicular to the surface of $\mathrm{TiO}_{2}{ }^{70}$

2.5. Electron Injection. The efficient transfer of electrons from the LUMO of dye to the semiconductor $\mathrm{CB}$ is an important parameter that decides the DSSC performance. ${ }^{15}$ The electron injection efficiency is quantified by the electron injection driving force $\left(\Delta G_{\text {inj }}^{0}\right)$, which can be calculated using eq 6

$$
\Delta G_{\text {inj }}=E_{\mathrm{CB}}-E^{\text {dye* }}=E_{\mathrm{CB}}-\left(E^{\text {dye }}+E_{0-0}\right)
$$

Here, $E_{\mathrm{CB}}$ refers to the $\mathrm{TiO}_{2} \mathrm{CB}$ lying at $-4.0 \mathrm{eV}, E^{\text {dye }}$ and $E^{\text {dye } *}$ represent the dye oxidation potential in its ground state and excited state, respectively, and $E_{0-0}$ refers to the vertical transition energy. According to Koopman's theorem, $E^{\text {dye }}$ can be calculated by taking negative of the dye $E_{\mathrm{HOMO}} \cdot{ }^{717}$ Another parameter that is worth mentioning is the total internal reorganizational energy $\left(\lambda_{\text {total }}\right)$, which can be calculated by employing the DFT method. The reorganizational energy $\left(\lambda_{\text {total }}\right)$ can be calculated by adding together the electron reorganizational energy $\left(\lambda_{\mathrm{e}}\right)$ with the hole reorganizational energy $\left(\lambda_{\mathrm{h}}\right)$ via eqs 7 and $8^{72}$

$$
\begin{aligned}
& \lambda_{\mathrm{e}}=\left(E_{0}^{-}-E_{-}\right)+\left(E_{0}^{-}-E_{0}\right) \\
& \lambda_{\mathrm{h}}=\left(E_{0}^{+}-E_{+}\right)+\left(E_{0}^{+}-E_{0}\right)
\end{aligned}
$$

where $E_{0}^{-}$and $E_{0}^{+}$represent the energies of the anionic state and the cationic state of the optimized molecules, respectively, in their neutral ground state, $E_{-}$and $E_{+}$denote the energies of the anionic state and cationic state of the molecules in their optimized anionic and cationic states, respectively, and $E_{0}$ 
Table 6. Calculated Driving Force for Electron Injection $\left(\Delta G_{\text {inj }}\right)$, Electron Reorganizational Energies $\left(\lambda_{\mathrm{e}}\right)$, Hole Reorganizational Energies $\left(\lambda_{\mathrm{h}}\right)$, Total Reorganizational Energies $\left(\lambda_{\text {total }}\right)$, and Excited-State Lifetimes $\left(\tau_{\mathrm{e}}\right)$ for All of the Designed Dyes (D1, D1T, D1F, and D1P)

\begin{tabular}{|c|c|c|c|c|c|c|c|}
\hline dye & $E^{\text {dye }}$ & $E_{0-0}$ & $\Delta G_{\text {inj }}$ & $\tau_{\mathrm{e}}(\mathrm{ns})$ & $\lambda_{\mathrm{h}}$ & $\lambda_{\mathrm{e}}$ & $\lambda_{\text {total }}$ \\
\hline D1 & -5.30 & 2.65 & -1.35 & 5.85 & 0.2244 & 0.2954 & 0.5199 \\
\hline D1T & -5.31 & 2.39 & -1.08 & 3.39 & 0.1716 & 0.2243 & 0.3960 \\
\hline D1F & -5.30 & 2.38 & -1.08 & 3.45 & 0.1682 & 0.2487 & 0.4170 \\
\hline D1P & -5.30 & 2.35 & -1.05 & 3.7 & 0.1604 & 0.2406 & 0.4010 \\
\hline
\end{tabular}

indicates the energy of the optimized molecule in the neutral ground state.

The total internal reorganizational energy $\left(\lambda_{\text {total }}\right)$ values for various dyes followed the order: D1 $(0.5199 \mathrm{eV})>\mathrm{D} 1 \mathrm{~F}$ $(0.4170 \mathrm{eV})>\mathrm{D} 1 \mathrm{P}(0.4010 \mathrm{eV})>\mathrm{D} 1 \mathrm{~T}(0.3960 \mathrm{eV})$. It is noted that there is a marginal difference between electron reorganizational energy $\left(\lambda_{\mathrm{e}}\right)$ and hole reorganizational energy $\left(\lambda_{\mathrm{h}}\right)$ values, which suggests that a better equilibrium is established between them leading to high-performance of DSSCs. ${ }^{15}$

The $\left(\Delta G_{\text {inj }}^{0}\right)$ values together with the electron reorganizational energies $\left(\lambda_{\mathrm{e}}\right)$, hole reorganizational energies $\left(\lambda_{\mathrm{h}}\right)$, and total reorganizational energies are given in Table 6 . The $\left(\Delta G_{\text {inj }}^{0}\right)$ values of all of the designed dyes are negative, which leads to better charge transfer from the dye LUMO to the semiconductor CB as listed in Table 6.

2.6. Excited-State Electron Lifetime. After the absorption of light by the dye molecule, the electrons are excited to higher-energy level. The longer the time spent in the excited state of the dye, the higher will be the likelihood of electron injection into the conduction band of the semiconductor. Therefore, the excited-state lifetimes $\left(\tau_{\mathrm{e}}\right)$ were calculated according to the following equation

$$
\tau_{\mathrm{e}}=\frac{1.499}{f E_{0-0}^{2}}
$$

where $f$ represents the oscillator strength and $E_{0-0}$ denotes the excitation energies of the different electronic states $\left(\mathrm{cm}^{-1}\right)$. The excited-state electron lifetimes were calculated for all of the dyes D1, D1T, D1F, and D1P, and are presented in Table 6.

2.7. Open-Circuit Voltage. In addition to the short-circuit current density, the open-circuit voltage $\left(V_{\text {oc }}\right)$ is another important factor that determines the conversion efficiency of a DSSC. The $V_{\text {oc }}$ can be calculated by subtracting the electrolyte redox potential from the semiconductor $\mathrm{CB}$ minimum energy $\left(E_{\mathrm{CBM}}\right)$ level via eq $9^{73}$

$$
V_{\mathrm{oc}}=\frac{E_{\mathrm{CBM}}-E_{\text {redox }}}{q}+\frac{K_{\mathrm{B}} T}{q} \ln \left(\frac{n_{\mathrm{c}}}{N_{\mathrm{B}}}\right)
$$

In eq $9, E_{\mathrm{CBM}}$ refers to the $E_{\mathrm{CBM}}$ of $\mathrm{TiO}_{2}, E_{\text {redox }}$ indicates the standard redox potential of $\mathrm{I}^{-} / \mathrm{I}_{3}^{-}$redox couple, which is -5.04 $\mathrm{eV}, K_{\mathrm{B}}$ is the Boltzmann constant whose value is $8.617 \times 10^{-5}$ $\mathrm{eV} \mathrm{K}^{-1}, T$ is the temperature in Kelvin set to be at $300 \mathrm{~K}, q$ is the elementary charge equal to $1.602 \times 10^{-19} \mathrm{C}, n_{\mathrm{c}}$ is an experimental quantity whose value was chosen to be $1.08 \times$ $10^{21} \mathrm{~cm}^{-3}, 74$ and $N_{\mathrm{CB}}$ denotes the density of electronic states, which was taken to be $7.00 \times 10^{20} \mathrm{~cm}^{-3}$.

The various photoelectrochemical parameters of all of the designed dyes such as $J_{\text {so }} V_{\text {oc }}$ and PCE are presented in Table 7 , which suggests that the $V_{\text {oc }}$ values of the dyes exhibited the following order: D1 $(801 \mathrm{mV})>\mathrm{D} 1 \mathrm{P}(731 \mathrm{mV})>\mathrm{D} 1 \mathrm{~F}(681$
Table 7. Calculated $J_{s c}, V_{\text {oc }}$ and PCE Values of All of the Designed Dyes (D1, D1T, D1F, and D1P)

\begin{tabular}{lcccc} 
dye & $J_{\text {sc }}\left(\mathrm{mA} \mathrm{cm}^{-2}\right)$ & $V_{\text {oc }}(\mathrm{mV})$ & FF & PCE (\%) \\
D1 & 16.4 & 801 & 0.68 & 8.93 \\
D1T & 26.2 & 631 & 0.68 & 11.25 \\
D1F & 26.2 & 681 & 0.68 & 12.13 \\
D1P & 27.2 & 731 & 0.68 & 13.5 \\
\hline
\end{tabular}

$\mathrm{mV})>\mathrm{D} 1 \mathrm{~T}(631 \mathrm{mV})$. The $V_{\mathrm{oc}}$ values of D1P, D1F, and D1T are smaller than that of $\mathrm{D} 1$, which is possibly caused by the lower shift of $\mathrm{TiO}_{2} E_{\mathrm{CBM}}$ induced by D1T, D1F, and D1P compared to D1 (Table 6). Nevertheless, the overall maximum solar-to-electric power conversion efficiency was shown by D1P based on other photoelectric parameters.

2.8. Power Conversion Efficiency (PCE). The PCE provides a basis for the design of high-conversion-efficiency DSSCs and can be determined by theoretical methods using eq $10^{76}$

$$
\mathrm{PCE}=\frac{V_{\mathrm{o}} J_{\mathrm{sc}}}{\left(P_{\mathrm{in}}\right)} \mathrm{FF}
$$

where FF refers to the fill factor, which was set at 0.68 , and $P_{\text {inj }}$ denotes the power of the incident light $\left(P_{\text {in }}=100 \mathrm{~mW} \mathrm{~cm}^{-2}\right.$ at AM 1.5). It is observed (Table 7) that the PCE values of D1T, $\mathrm{D} 1 \mathrm{~F}$, and $\mathrm{D} 1 \mathrm{P}$ are $11.25,12.13$, and $13.50 \%$, respectively. The maximum PCE value obtained for D1P is attributed to the efficient light-harvesting capabilities of the dye as a result of improved broadening of its UV-vis absorption spectrum. It can be noted that the designed D1T, D1F, and D1P dyes showed relatively lower values for $V_{\mathrm{oc}}$ compared to that of $\mathrm{D} 0$, yet they displayed large PCEs (a maximum of 13.50\%) owing to higher $J_{s c}$ values, thus confirming that the light-harvesting performance of BODIPY-carbazole has been improved with the proposed structural modification.

\section{CONCLUSIONS}

In this study, we demonstrated the rational design of BODIPYcarbazole (D- $\pi$-A-A) dyads for DSSC application using DFT calculations. The photoelectric properties of the designed dyes were improved by substituting electron-donating groups at the electron-rich carbazole moiety and electron acceptor groups at the BODIPY core, which resulted in a decreased band gap of the designed dyes. Further modification was demonstrated by the incorporation of heterocyclic thiophene, furan, and phosphole rings into BODIPY-carbazole moiety, which resulted in the red-shifting of light absorption spectra and consequently improved the power conversion efficiency. The interactions between the dye and semiconductor were modeled by employing their bridged-bidentate models of the dyes over $\left(\mathrm{TiO}_{2}\right)_{38}$ nanoclusters. The $\mathrm{CB}$ shift of the semiconductor $\left(E_{\mathrm{CBM}}\right)$ induced by the designed dyes was lower, which resulted in a decrease in the $V_{\text {oc }}$ values, which was however 
compensated by a substantial increase in the $J_{\text {sc }}$ values, thus resulting in the enhancement of PCE values. This work provides a detailed understanding of the electron-donating and electron-accepting properties and $\pi$-conjugation, which can be manipulated to tune the photoelectric properties of the photosensitizers leading to the improved PCE of DSSCs.

\section{COMPUTATIONAL DETAILS}

All of the calculations were carried out using density functional theory (DFT) and time-dependent density functional theory (TD-DFT) with the Gaussian 09 software package ${ }^{77}$ (version: Gaussian 09 Revision-D.01-SMP). Both gas-phase and solventphase optimizations were conducted for all of the designed dye molecules. To account for the solvent effects, the conductorlike polarizable continuum model of dichloromethane (CPCM) was utilized. All of the designed dye molecules were fully optimized in ground state and ionic state in gas phase using the B3LYP/6-311G $(\mathrm{d}, \mathrm{p})$ method. The frequency calculations were performed in the gas phase with the same functional and basis set. There were no imaginary frequencies (see Tables S1-S4 in the Supporting Information), which represents minimum-energy structures for molecules. ${ }^{56}$ The UV-visible spectra of the dyes were simulated at the TD-DFT level of theory. These calculations were performed on the ground-state structure using the CAM-B3LYP/6-311G(d,p) method. It has been demonstrated by previous reports that the CAM-B3LYP functional gives rise to reasonable results. ${ }^{72,78}$ Furthermore, the reliability of our calculations was tested by calculating the UV-vis absorption spectrum of the already synthesized dye UY1 by Mao et al. ${ }^{79}$ It was seen that the calculated value of the maximum absorption wavelength $\left(\lambda_{\max }\right)$ of $522 \mathrm{~nm}$ was close to the experimental value of $530 \mathrm{~nm}$, suggesting that our method of calculation is reliable.

To understand the surface interactions between the dyes and the semiconductor, the $\left(\mathrm{TiO}_{2}\right)_{38}$ nanocluster model was employed to simulate the semiconductor (101) surface. The $\left(\mathrm{TiO}_{2}\right)_{38}$ nanocluster was created by carefully cutting a slab of anatase so as the majority (101) surface is exposed. The cluster gives accurate results and saves the computational cost ${ }^{80}$ It has been demonstrated that the lowest-excited energy of the $\left(\mathrm{TiO}_{2}\right)_{38}$ nanocluster $(3.2 \mathrm{eV})$ is very close to the experimental value. ${ }^{78}$ Previous study has revealed various modes through which adsorption of the dye on the $\left(\mathrm{TiO}_{2}\right)_{38}$ nanocluster may occur. The bridged-bidentate geometry, which involves the transfer of hydrogen atom to the oxygen atom on the surface, is considered to be a stable configuration. ${ }^{81}$ The ground-state structures of the isolated dyes, $\left(\mathrm{TiO}_{2}\right)_{38}$ nanocluster, and dye/ $\left(\mathrm{TiO}_{2}\right)_{38}$ complexes were optimized using generalized gradient approximation (GGA) and Perdew-Burke-Ernzerhof (PBE) functional with double-numerical polarization (DNP) basis set in the $\mathrm{DMol}^{82}$ program of Materials Studio 7 software package. The optimized dye/( $\left.\mathrm{TiO}_{2}\right)_{38}$ complexes were subjected to single-point energy calculations. The dye/ $\left(\mathrm{TiO}_{2}\right)_{38}$ orbitals were also calculated. The density of states (DOS) spectra were plotted using GaussSum 3.0. ${ }^{83}$

The BODIPY dyes were designed by attaching a carbazole moiety to the BODIPY core at the meso position through a phenyl ring as the $\pi$-spacer and by substituting an electrondonating- $\mathrm{N}\left(\mathrm{CH}_{3}\right)_{2}$ group at the carbazole moiety and two electron-accepting - $\mathrm{COOH}$ at the BODIPY core. Initially, a simplified molecular structure containing only carbazole moiety attached to the BODIPY core through phenyl ring as $\pi$-spacer was designed and was named D0. Then, an electron- donating $-\mathrm{N}\left(\mathrm{CH}_{3}\right)_{2}$ group and two electron-accepting $-\mathrm{COOH}$ groups were introduced and the resulting dye was named as D1. The dye D0 was used as a reference to check the effect of substitution of electron-donating and electronaccepting groups. The dye D1 was used as the basis for the design of three more dyes in which heterocyclic rings such as thiophene, furan, and phosphole were fused into the BODIPY core to extend the $\pi$ conjugation as shown in Figure 2. These dyes were named as $\mathrm{D} 1 \mathrm{~T}, \mathrm{D} 1 \mathrm{~F}$, and $\mathrm{D} 1 \mathrm{P}$, respectively.

\section{ASSOCIATED CONTENT}

\section{S) Supporting Information}

The Supporting Information is available free of charge at https://pubs.acs.org/doi/10.1021/acsomega.1c02121.

Optimized structures of all of the designed dyes (Figure S1), vibrational frequencies (Tables S1-S4), unoptimized structure of the $\left(\mathrm{TiO}_{2}\right)_{38}$ nanocluster (Figure S2), and the optimized structure of the $\left(\mathrm{TiO}_{2}\right)_{38}$ nanocluster (Figure S3) (PDF)

Ground-state optimized structures of all of the designed dyes (D1, D1T, D1F, and D1P) (ZIP)

Optimized structures of the $\left(\mathrm{TiO}_{2}\right)_{38}$ nanocluster (ZIP)

\section{AUTHOR INFORMATION}

\section{Corresponding Authors}

Ata Ur Rahman - Institute of Chemical Sciences, University of Peshawar, Peshawar 25120, Pakistan; Email: atasafi@ uop.edu.pk

Gul Rahman - Institute of Chemical Sciences, University of Peshawar, Peshawar 25120, Pakistan; ○ orcid.org/00000003-1335-146X; Email: gul_rahman47@uop.edu.pk

\section{Authors}

Muhammad Bilal Khan - Institute of Chemical Sciences, University of Peshawar, Peshawar 25120, Pakistan

Muhammad Yaseen - Institute of Chemical Sciences, University of Peshawar, Peshawar 25120, Pakistan

Complete contact information is available at: https://pubs.acs.org/10.1021/acsomega.1c02121

\section{Notes}

The authors declare no competing financial interest. All input data required for reproducing this work are available in the Supporting Information.

\section{ACKNOWLEDGMENTS}

The authors gratefully acknowledge the financial support by the Higher Education Commission of Pakistan, Islamabad, under National Research Program for Universities (NRPU) project No. 7600/KPK/NRPU/R\&D/HEC/2017.

\section{REFERENCES}

(1) Karmaker, A. K.; Rahman, M. M.; Hossain, M. A.; Ahmed, M. R. Exploration and corrective measures of greenhouse gas emission from fossil fuel power stations for Bangladesh. J. Cleaner Prod. 2020, 244, No. 118645.

(2) Liu, H.; Liu, L.; Fu, Y.; Liu, E.; Xue, B. Theoretical Design of $\mathrm{D}-\pi-\mathrm{A}-\mathrm{A}$ Sensitizers with Narrow Band Gap and Broad Spectral Response Based on Boron Dipyrromethene for Dye-Sensitized Solar Cells. J. Chem. Inf. Model. 2019, 59, 2248-2256.

(3) Rahman Mohamed, A.; Lee, K. T. Energy for sustainable development in Malaysia: Energy policy and alternative energy. Energy Policy 2006, 34, 2388-2397. 
(4) Roy-Mayhew, J. D.; Bozym, D. J.; Punckt, C.; Aksay, I. A. Functionalized graphene as a catalytic counter electrode in dyesensitized solar cells. ACS Nano 2010, 4, 6203-6211.

(5) Samanta, P. N.; Majumdar, D.; Roszak, S.; Leszczynski, J. Firstprinciples approach for assessing cold electron injection efficiency of dye-sensitized solar cell: Elucidation of mechanism of charge injection and recombination. J. Phys. Chem. C 2020, 124, 2817-2836.

(6) Wang, F.; Langford, S.; Nakai, H. Robust design of D- $\pi$-A model compounds using digital structures for organic DSSC applications. J. Mol. Graphics 2021, 102, No. 107798.

(7) Lee, C.-P.; Li, C.-T.; Ho, K.-C. Use of organic materials in dyesensitized solar cells. Mater. Today 2017, 20, 267-283.

(8) Ji, J. M.; Zhou, H.; Eom, Y. K.; Kim, C. H.; Kim, H. K. 14.2\% Efficiency Dye-Sensitized Solar Cells by Co-sensitizing Novel Thieno $[3,2-b]$ indole-Based Organic Dyes with a Promising Porphyrin Sensitizer. Adv. Energy Mater. 2020, 10, No. 2000124.

(9) Colombo, A.; Dragonetti, C.; Roberto, D.; Fagnani, F. Copper Complexes as Alternative Redox Mediators in Dye-Sensitized Solar Cells. Molecules 2021, 26, No. 194.

(10) Chalkias, D.; Verykokkos, N.; Kollia, E.; Petala, A.; Kostopoulos, V.; Papanicolaou, G. High-efficiency quasi-solid state dye-sensitized solar cells using a polymer blend electrolyte with "polymer-in-salt" conduction characteristics. Sol. Energy 2021, 222, $35-47$.

(11) Cao, Y.; Saygili, Y.; Ummadisingu, A.; Teuscher, J.; Luo, J.; Pellet, N.; Giordano, F.; Zakeeruddin, S. M.; Moser, J.-E.; Freitag, M. $11 \%$ efficiency solid-state dye-sensitized solar cells with copper (II/I) hole transport materials. Nat. Commun. 2017, 8, No. 15390.

(12) Ge, Z.; Wang, C.; Chen, Z.; Wang, T.; Chen, T.; Shi, R.; Yu, S.; Liu, J. Investigation of the $\mathrm{TiO} 2$ nanoparticles aggregation with high light harvesting for high-efficiency dye-sensitized solar cells. Mater. Res. Bull. 2021, 135, No. 111148.

(13) Godfroy, M.; Liotier, J.; Mwalukuku, V. M.; Joly, D.; Huaulmé, Q.; Cabau, L.; Aumaitre, C.; Kervella, Y.; Narbey, S.; Oswald, F. Benzothiadiazole-based photosensitizers for efficient and stable dyesensitized solar cells and $8.7 \%$ efficiency semi-transparent minimodules. Sustainable Energy Fuels 2021, 5, 144-153.

(14) Al-Faouri, T.; Buguis, F. L.; Azizi Soldouz, S.; Sarycheva, O. V.; Hussein, B. A.; Mahmood, R.; Koivisto, B. D. Exploring StructureProperty Relationships in a Bio-Inspired Family of Bipodal and Electronically-Coupled Bistriphenylamine Dyes for Dye-Sensitized Solar Cell Applications. Molecules 2020, 25, No. 2260.

(15) Yang, Z.; Liu, C.; Li, K.; Cole, J. M.; Shao, C.; Cao, D. Rational Design of Dithienopicenocarbazole-Based Dyes and a Prediction of Their Energy-Conversion Efficiency Characteristics for Dye-Sensitized Solar Cells. ACS Appl. Energy Mater. 2018, 1, 1435-1444.

(16) Delgado-Montiel, T.; Baldenebro-López, J.; Soto-Rojo, R.; Glossman-Mitnik, D. Theoretical Study of the Effect of $\pi$-Bridge on Optical and Electronic Properties of Carbazole-Based Sensitizers for DSSCs. Molecules 2020, 25, No. 3670.

(17) Divya, V. V.; Suresh, C. H. Design and DFT study of nitrogenrich donor systems for improved photovoltaic performance in dyesensitized solar cells. New J. Chem. 2021, 45, 11585-11595.

(18) Dayan, S.; Kayaci, N.; Özpozan, N. K. Improved performance with molecular design of Ruthenium (II) complexes bearing diaminebased bidentate ligands as sensitizer for dye-sensitized solar cells (DSSC). J. Mol. Struct. 2020, 1209, No. 127920.

(19) Subramaniam, K.; Athanas, A. B.; Kalaiyar, S. Dual anchored Ruthenium (II) sensitizer containing 4-Nitro-phenylenediamine Schiff base ligand for dye sensitized solar cell application. Inorg. Chem. Commun. 2019, 104, 88-92.

(20) Park, J. M.; Lee, J. H.; Jang, W.-D. Applications of porphyrins in emerging energy conversion technologies. Coord. Chem. Rev. 2020, 407, No. 213157.

(21) Jahantigh, F.; Ghorashi, S. B.; Bayat, A. Hybrid dye sensitized solar cell based on single layer graphene quantum dots. Dyes Pigm. 2020, 175, No. 108118.

(22) Patni, N.; G Pillai, S.; Sharma, P. Effect of using betalain, anthocyanin and chlorophyll dyes together as a sensitizer on enhancing the efficiency of dye-sensitized solar cell. Int. J. Energy Res. 2020, 44, 10846-10859.

(23) Ferdowsi, P.; Saygili, Y.; Jazaeri, F.; Edvinsson, T.; Mokhtari, J.; Zakeeruddin, S. M.; Liu, Y.; Grätzel, M.; Hagfeldt, A. Molecular Engineering of Simple Metal-Free Organic Dyes Derived from Triphenylamine for Dye-Sensitized Solar Cell Applications. ChemSusChem 2020, 13, 212-220.

(24) Su, R.; Lyu, L.; Elmorsy, M. R.; El-Shafei, A. Novel metal-free organic dyes constructed with the DDI A- $\pi$-A motif: Sensitization and co-sensitization study. J. Sol. Energy 2019, 194, 400-414.

(25) Abusaif, M. S.; Fathy, M.; Abu-Saied, M.; Elhenawy, A. A.; Kashyout, A.; Selim, M. R.; Ammar, Y. A. New carbazole-based organic dyes with different acceptors for dye-sensitized solar cells: Synthesis, characterization, dssc fabrications and density functional theory studies. J. Mol. Struct. 2021, 1225, No. 129297.

(26) Tian, L.; Wang, Y.; Zhang, Y.; Li, X.; Wu, W.; Liu, B. Molecular Engineering of Indoline Dyes and Their Application in Dye-Sensitized Solar Cells: Effect of Planarity and Side Chain on Interfacial ChargeTransfer Processes. ACS Appl. Energy Mater. 2020, 4, 242-248.

(27) Ayare, N. N.; Sharma, S.; Sonigara, K. K.; Prasad, J.; Soni, S. S.; Sekar, N. Synthesis and computational study of coumarin thiophenebased D- $\pi$-A azo bridge colorants for DSSC and NLOphoric application. J. Photochem. Photobiol., A 2020, 394, No. 112466.

(28) Duffy, M. P.; Delaunay, W.; Bouit, P.-A.; Hissler, M. $\pi$ Conjugated phospholes and their incorporation into devices: components with a great deal of potential. Chem. Soc. Rev. 2016, 45, 5296-5310.

(29) Jie, J.; Xu, Q.; Yang, G.; Feng, Y.; Zhang, B. Porphyrin sensitizers involving a fluorine-substituted benzothiadiazole as auxiliary acceptor and thiophene as $\pi$ bridge for use in dye-sensitized solar cells (DSSCs). Dyes Pigm. 2020, 174, No. 107984.

(30) Han, L.; Yu, H.; Chen, Q.; Lu, Y.; He, J.; Jiang, S. Triphenylamine dyes bearing 5-phenyl-2-(arylthiophen-2-yl) thiazole bridge for dye sensitized solar cells. Dyes Pigm. 2020, 187, No. 109092.

(31) Kandregula, G. R.; Mandal, S.; Prince, G.; Yadav, S. K.; Ramanujam, K. A computational study on boron dipyromethene ancillary acceptor-based dyes for dye-sensitized solar cells. New. J. Chem. 2020, 44, 4877-4886.

(32) Liu, H.; Liu, L.; Fu, Y.; Liu, E.; Xue, B. Theoretical Design of D $-\pi-A-A$ Sensitizers with Narrow Band Gap and Broad Spectral Response Based on Boron Dipyrromethene for Dye-Sensitized Solar Cells. J. Chem. Inf. Model. 2019, 59, 2248-2256.

(33) Joly, D.; Pellejà, L.; Narbey, S.; Oswald, F.; Chiron, J.; Clifford, J. N.; Palomares, E.; Demadrille, R. A robust organic dye for dye sensitized solar cells based on iodine/iodide electrolytes combining high efficiency and outstanding stability. Sci. Rep. 2015, 4, No. 4033.

(34) Over, H. Surface chemistry of ruthenium dioxide in heterogeneous catalysis and electrocatalysis: from fundamental to applied research. Chem. Rev. 2012, 112, 3356-3426.

(35) Mun, C.; Cantrel, L.; Madic, C. Review of literature on ruthenium behavior in nuclear power plant severe accidents. Nucl. Technol. 2006, 156, 332-346.

(36) Wang, D.; Fan, J.; Gao, X.; Wang, B.; Sun, S.; Peng, X. Carboxyl BODIPY Dyes from Bicarboxylic Anhydrides: One-Pot Preparation, Spectral Properties, Photostability, and Biolabeling. J. Org. Chem. 2009, 74, 7675-7683.

(37) Adarsh, N.; Avirah, R. R.; Ramaiah, D. Tuning Photosensitized Singlet Oxygen Generation Efficiency of Novel Aza-BODIPY Dyes. Org. Lett. 2010, 12, 5720-5723.

(38) Squeo, B. M.; Pasini, M. BODIPY platform: a tunable tool for green to NIR OLEDs. Supramol. Chem. 2020, 32, 56-70.

(39) Treibs, A.; Kreuzer, F. H. Difluorboryl-komplexe von di-und tripyrrylmethenen. Justus Liebigs Ann. Chem. 1968, 718, 208-223.

(40) Hattori, S.; Ohkubo, K.; Urano, Y.; Sunahara, H.; Nagano, T.; Wada, Y.; Tkachenko, N. V.; Lemmetyinen, H.; Fukuzumi, S. Charge Separation in a Nonfluorescent Donor-Acceptor Dyad Derived from Boron Dipyrromethene Dye, Leading to Photocurrent Generation. J. Phys. Chem. B 2005, 109, 15368-15375. 
(41) Liao, J.; Zhao, H.; Xu, Y.; Zhou, W.; Peng, F.; Wang, Y.; Fang, Y. Novel BODIPY dyes with electron donor variety for dye-sensitized solar cells. RSC Adv. 2017, 7, 33975-33985.

(42) Wang, J.; Boens, N.; Jiao, L.; Hao, E. Aromatic [b]-fused BODIPY dyes as promising near-infrared dyes. Org. Biomol. Chem. 2020, 18, 4135-4156.

(43) Shah, M. F.; Mirloup, A.; Chowdhury, T. H.; Sutter, A.; Hanbazazah, A. S.; Ahmed, A.; Lee, J.-J.; Abdel-Shakour, M.; Leclerc, N.; Kaneko, R.; Islam, A. Cross-conjugated BODIPY pigment for highly efficient dye sensitized solar cells. Sustain. Energy Fuels 2020, 4, $1908-1914$

(44) Tsumura, S.; Ohira, K.; Hashimoto, K.; Imato, K.; Ooyama, Y. Synthesis, optical and electrochemical properties of propeller-type 3,5,8-trithienyl-BODIPY dyes. Mater. Chem. Front. 2020, 4, 27622771

(45) Shah, M. F.; Mirloup, A.; Chowdhury, T. H.; Alexandra, S.; Hanbazazah, A. S.; Ahmed, A.; Lee, J.-J.; Leclerc, N.; Abdel-Shakour, M.; Islam, A. A near-infrared thienyl-BODIPY co-sensitizer for highefficiency dye-sensitized solar cells. Sustainable Energy Fuels 2019, 3, $2983-2989$.

(46) Zha, J.-Y.; Lin, Y.-H.; Xu, J.-C.; Zhang, Y.-L.; Zeng, L.-T. Synthesis and Spectroscopic Properties of Some Novel BODIPY Dyes. Spectrosc. Spectral Anal. 2014, 34, 3034-3039.

(47) Wang, L.; Verbelen, B.; Tonnelé, C.; Beljonne, D.; Lazzaroni, R.; Leen, V.; Dehaen, W.; Boens, N. UV-vis spectroscopy of the coupling products of the palladium-catalyzed $\mathrm{C}-\mathrm{H}$ arylation of the BODIPY core. Photochem. Photobiol. Sci. 2013, 12, 835-847.

(48) Ooyama, Y.; Hagiwara, Y.; Mizumo, T.; Harima, Y.; Ohshita, J. Synthesis of diphenylamino-carbazole substituted BODIPY dyes and their photovoltaic performance in dye-sensitized solar cells. RSC $A d v$. 2013, 3, 18099-18106.

(49) Strahan, J.; Popere, B. C.; Khomein, P.; Pointer, C. A.; Martin, S. M.; Oldacre, A. N.; Thayumanavan, S.; Young, E. R. Modulating absorption and charge transfer in bodipy-carbazole donor-acceptor dyads through molecular design. Dalton Trans. 2019, 48, 8488-8501.

(50) Kesavan, P. E.; Behera, R. N.; Mori, S.; Gupta, I. Carbazole substituted BODIPYs: synthesis, computational, electrochemical and DSSC studies. J. Fluoresc. 2017, 27, 2131-2144.

(51) Mao, L.; Wu, Y.; Jiang, J.; Guo, X.; Heng, P.; Wang, L.; Zhang, J. Rational Design of Phenothiazine-Based Organic Dyes for DyeSensitized Solar Cells: The Influence of $\pi$-Spacers and Intermolecular Aggregation on Their Photovoltaic Performances. J. Phys. Chem. C 2020, 124, 9233-9242.

(52) Mahmood, A.; Tang, A.; Wang, X.; Zhou, E. First-principles theoretical designing of planar non-fullerene small molecular acceptors for organic solar cells: manipulation of noncovalent interactions. Phys. Chem. Chem. Phys. 2019, 21, 2128-2139.

(53) Wang, R.; Chen, Q.; Feng, H.; Liu, B. Simple adjustments to the molecular planarity of organic sensitizers: towards highly selective optimization of energy levels. New J. Chem. 2017, 41, 11853-11859.

(54) So, H.; Kim, J. H.; Lee, J. H.; Hwang, H.; An, D. K.; Lee, K. M. Planarity of terphenyl rings possessing o-carborane cages: turning on intramolecular-charge-transfer-based emission. Chem. Commun. 2019, $55,14518-14521$.

(55) Martsinovich, N.; Troisi, A. Theoretical studies of dyesensitised solar cells: from electronic structure to elementary processes. Energy Environ. Sci. 2011, 4, 4473-4495.

(56) Khan, M. U.; Khalid, M.; Ibrahim, M.; Braga, A. A. C.; Safdar, M.; Al-Saadi, A. A.; Janjua, M. R. S. A. First Theoretical Framework of Triphenylamine-Dicyanovinylene-Based Nonlinear Optical Dyes: Structural Modification of $\pi$-Linkers. J. Phys. Chem. C 2018, 122, 4009-4018.

(57) De Angelis, F.; Fantacci, S.; Selloni, A. Alignment of the dye's molecular levels with the TiO2band edges in dye-sensitized solar cells: a DFT-TDDFT study. Nanotechnology 2008, 19, No. 424002.

(58) Fitri, A.; Benjelloun, A. T.; Benzakour, M.; McHarfi, M.; Hamidi, M.; Bouachrine, M. Theoretical investigation of new thiazolothiazole-based D- $\pi$-A organic dyes for efficient dye-sensitized solar cell. Spectrochim. Acta, Part A 2014, 124, 646-654.
(59) Islam, A.; Sugihara, H.; Arakawa, H. Molecular design of ruthenium (II) polypyridyl photosensitizers for efficient nanocrystalline TiO2 solar cells. J. Photochem. Photobiol., A 2003, 158, 131-138. (60) Li, M.; Kou, L.; Diao, L.; Zhang, Q.; Li, Z.; Wu, Q.; Lu, W.; Pan, D.; Wei, Z. Theoretical study of WS-9-based organic sensitizers for unusual Vis/NIR absorption and highly efficient dye-sensitized solar cells. J. Phys. Chem. C 2015, 119, 9782-9790.

(61) Chaurasia, S.; Liang, C.-J.; Yen, Y.-S.; Lin, J. T. Sensitizers with rigidified-aromatics as the conjugated spacers for dye-sensitized solar cells. J. Mater. Chem. C 2015, 3, 9765-9780.

(62) Heng, P.; An, B.; Ren, H.; Hu, Y.; Guo, X.; Mao, L.; Wang, L.; Zhang, J. Influence of Different Molecular Design Strategies on Photovoltaic Properties of a Series of Triphenylamine-Based Organic Dyes for Dye-Sensitized Solar Cells: Insights from Theoretical Investigations. J. Phys. Chem. C 2020, 124, 15036-15044.

(63) Elmorsy, M. R.; Su, R.; Fadda, A. A.; Etman, H.; Tawfik, E. H.; El-Shafei, A. Molecular engineering and synthesis of novel metal-free organic sensitizers with $\mathrm{D}-\pi$-A- $\pi$-A architecture for DSSC applications: the effect of the anchoring group. Dyes Pigm. 2018, 158, 121130.

(64) Ondersma, J. W.; Hamann, T. W. Recombination and redox couples in dye-sensitized solar cells. Coord. Chem. Rev. 2013, 257, $1533-1543$.

(65) Zhang, M.; Zhang, J.; Bai, Y.; Wang, Y.; Su, M.; Wang, P. Anion-correlated conduction band edge shifts and charge transfer kinetics in dye-sensitized solar cells with ionic liquid electrolytes. Phys. Chem. Chem. Phys. 2011, 13, 3788-3794.

(66) Zhang, W.; Heng, P.; Su, H.; Ren, T.; Wang, L.; Zhang, J. Rational design of high-efficiency organic dyes in dye-sensitized solar cells by multiscale simulations. J. Phys. Chem. C 2018, 122, 2521925228.

(67) Jiao, Y.; Ma, W.; Meng, S. Quinoid conjugated dye designed for efficient sensitizer in dye sensitized solar cells. Chem. Phys. Lett. 2013, $586,97-99$.

(68) Cherepy, N. J.; Smestad, G. P.; Grätzel, M.; Zhang, J. Z. Ultrafast Electron Injection: Implications for a Photoelectrochemical Cell Utilizing an Anthocyanin Dye-Sensitized TiO2 Nanocrystalline Electrode. J. Phys. Chem. B 1997, 101, 9342-9351.

(69) Luo, J.; Zhou, J.; Guo, H.; Yang, W.; Liao, B.; Shi, W.; Chen, Y. Effects of Ag-ion implantation on the performance of DSSCs with a tri-layer TiO2 film. RSC Adv. 2014, 4, 56318-56322.

(70) Moehl, T.; Tsao, H. N.; Wu, K.-L.; Hsu, H.-C.; Chi, Y.; Ronca, E.; De Angelis, F.; Nazeeruddin, M. K.; Grätzel, M. High OpenCircuit Voltages: Evidence for a Sensitizer-Induced TiO2 Conduction Band Shift in $\mathrm{Ru}(\mathrm{II})$-Dye Sensitized Solar Cells. Chem. Mater. 2013, 25, 4497-4502.

(71) Pearson, R. G. Absolute electronegativity and hardness: application to inorganic chemistry. Inorg. Chem. 1988, 27, 734-740. (72) Liu, H.; Li, B.; Xue, B.; Liu, E. Theoretical Design of HighPerformance Boron Dipyrromethenes Dyes by Introducing Heterocyclics to Tune Photoelectric Properties. J. Phys. Chem. C 2019, 123, 26047-26056.

(73) Ning, Z.; Fu, Y.; Tian, H. Improvement of dye-sensitized solar cells: what we know and what we need to know. Energy Environ. Sci. 2010, 3, 1170-1181.

(74) Sun, K.; Wang, L.; Mao, L.; Zhang, Y.; Liu, F.; Zhang, J. Influence of $\pi$ spacer of donor-acceptor- $\pi$-acceptor sensitizers on photovoltaic properties in dye-sensitized solar cells. Org. Electron. 2020, 76, No. 105429.

(75) Marinado, T.; Hagberg, D. P.; Hedlund, M.; Edvinsson, T.; Johansson, E. M. J.; Boschloo, G.; Rensmo, H.; Brinck, T.; Sun, L.; Hagfeldt, A. Rhodanine dyes for dye-sensitized solar cells: spectroscopy, energy levels and photovoltaic performance. Phys. Chem. Chem. Phys. 2009, 11, 133-141.

(76) Bourouina, A.; Rekhis, M. Structural and electronic study of iron-based dye sensitizers for solar cells using DFT/TDDFT. J. Mol. Model. 2017, 23, No. 310 .

(77) Frisch, M. J.; Trucks, G. W.; Schlegel, H. B.; Scuseria, G. E.; Robb, M. A.; Cheeseman, J. R.; Scalmani, G.; Barone, V.; Petersson, 
A. G.; et al. Gaussian 09, revision A.01; Gaussian, Inc.: Wallingford, CT, 2013.

(78) Yanai, T.; Tew, D. P.; Handy, N. C. A new hybrid exchangecorrelation functional using the Coulomb-attenuating method (CAMB3LYP). Chem. Phys. Lett. 2004, 393, 51-57.

(79) Mao, M.; Zhang, X.-L.; Fang, X.-Q.; Wu, G.-H.; Dai, S.-Y.; Song, Q.-H.; Zhang, X.-X. Highly efficient light-harvesting boradiazaindacene sensitizers for dye-sensitized solar cells featuring phenothiazine donor antenna. J. Power Sources 2014, 268, 965-976.

(80) De Angelis, F. Direct vs indirect injection mechanisms in perylene dye-sensitized solar cells: A DFT/TDDFT investigation. Chem. Phys. Lett. 2010, 493, 323-327.

(81) Ronca, E.; Pastore, M.; Belpassi, L.; Tarantelli, F.; De Angelis, F. Influence of the dye molecular structure on the $\mathrm{TiO} 2$ conduction band in dye-sensitized solar cells: disentangling charge transfer and electrostatic effects. Energy Environ. Sci. 2013, 6, 183-193.

(82) Perdew, J. P.; Burke, K.; Ernzerhof, M. Generalized Gradient Approximation Made Simple [Phys. Rev. Lett. 77, 3865 (1996)]. Phys. Rev. Lett. 1997, 78, 1396.

(83) O’boyle, N. M. T.; Langner, K. M.; O’Boyle, N. M. A library for package-independent computational chemistry algorithms. J. Comput. Chem. 2008, 29, 839-845. 